Recent Progress in the Development of Diesel Surrogate Fuels

William J. Pitz, Charles J. Mueller

December 11, 2009

Progress in Energy and Combustion Science 
This document was prepared as an account of work sponsored by an agency of the United States government. Neither the United States government nor Lawrence Livermore National Security, LLC, nor any of their employees makes any warranty, expressed or implied, or assumes any legal liability or responsibility for the accuracy, completeness, or usefulness of any information, apparatus, product, or process disclosed, or represents that its use would not infringe privately owned rights. Reference herein to any specific commercial product, process, or service by trade name, trademark, manufacturer, or otherwise does not necessarily constitute or imply its endorsement, recommendation, or favoring by the United States government or Lawrence Livermore National Security, LLC. The views and opinions of authors expressed herein do not necessarily state or reflect those of the United States government or Lawrence Livermore National Security, LLC, and shall not be used for advertising or product endorsement purposes. 


\title{
Recent Progress in the Development of Diesel Surrogate Fuels
}

\author{
William J. Pitz ${ }^{1}$ and Charles J. Mueller ${ }^{2}$ \\ ${ }^{1}$ Lawrence Livermore National Laboratory, Livermore, CA 94558 \\ ${ }^{2}$ Sandia National Laboratories, Livermore, CA 94550
}

\begin{abstract}
There has been much recent progress in the area of surrogate fuels for diesel. In the last few years, experiments and modeling have been performed on higher molecular weight components of relevance to diesel fuel such as n-hexadecane (n-cetane) and 2,2,4,4,6,8,8-heptamethylnonane (iso-cetane). Chemical kinetic models have been developed for all the n-alkanes up to 16 carbon atoms. Also, there has been much experimental and modeling work on lower molecular weight surrogate components such as n-decane and n-dodecane that are most relevant to jet fuel surrogates, but are also relevant to diesel surrogates where simulation of the full boiling point range is desired. For two-ring compounds, experimental work on decalin and tetralin recently has been published. For multi-component surrogate fuel mixtures, recent work on modeling of these mixtures and comparisons to real diesel fuel is reviewed. Detailed chemical kinetic models for surrogate fuels are very large in size. Significant progress also has been made in improving the mechanism reduction tools that are needed to make these large models practicable in multidimensional reacting flow simulations of diesel combustion. Nevertheless, major research gaps remain. In the case of iso-alkanes, there are experiments and modeling work on only one of relevance to diesel: iso-cetane. Also, the iso-alkanes in diesel are lightly branched and no detailed chemical kinetic models or experimental investigations are available for such compounds. More components are needed to fill out the iso-alkane boiling point range. For the aromatic class of compounds, there has been no new work for compounds in the boiling point range of diesel. Most of the new work has been on alkyl aromatics that are of the range C7 to C8, below the C10 to C20 range that is needed. For the chemical class of cycloalkanes, experiments and modeling on higher molecular weight components are warranted. Finally for multi-component surrogates needed to treat real diesel, the inclusion of higher molecular weight components is needed in models and experimental investigations.
\end{abstract}

Keywords: Diesel surrogate fuel; chemical kinetic model; hydrocarbon fuels; experimental validation data; reduced mechanisms; physical properties

\section{INTRODUCTION}

Detailed chemical kinetic models are important because they help enable the computational design and optimization of practical devices such as internal combustion engines by enabling simulation of the combustion of transportation fuels like gasoline, diesel, and jet fuels. Development of detailed chemical kinetic models is challenging. Gasoline, diesel and jet fuels 
derived from conventional petroleum sources are composed of hundreds of compounds. Development of models that represent all these components is prohibitive because the model would be too large for current computational resources. Also, all the fundamental data needed for development of such a model (e.g., chemical kinetic rate constants, reaction paths, thermodynamic parameters) are not available. Thus, simplified "surrogate fuels" are useful for representing current transportation fuels. A surrogate fuel is defined as a fuel composed of a small number of pure compounds whose behavior matches certain characteristics of a target fuel that contains many compounds (e.g., a market diesel fuel). Both the chemical and physical characteristics of the target fuel need to be represented by the surrogate fuel so that the surrogate will properly reproduce not only the combustion characteristics of the fuel, but also the injection, vaporization, and mixing processes that precede ignition in practical devices. Relevant chemical characteristics of the fuel may include ignition behavior, molecular structures, adiabatic flame temperature, $\mathrm{C} / \mathrm{H} / \mathrm{O}$ content, and sooting propensity. Relevant physical characteristics may include volatility parameters, density, viscosity, surface tension, and diffusion coefficients.

In addition to enabling accurate computational simulations, surrogate fuels are also useful experimentally. First, experimental data on surrogate fuels are needed to validate surrogate fuel models. Second, it is useful to develop surrogate fuels to provide standardized fuels whose compositions do not change over time. These standardized fuels can be used so that experiments are reproducible. They also allow testing of the same fuel in different experimental devices, geographic locations and using different analysis techniques so that comparisons can be made without fuel variability complicating interpretation of the results. The compositions of gasoline, diesel and jet fuels vary as the refinery streams and/or other blendstocks from which they are derived change with time. Even if standardized fuels are blended from refinery streams and stored for later use, there is only a finite volume of these standardized fuels available, and they could chemically deteriorate over time. In contrast, standardized fuels from surrogate components can be reformulated at any time from their constituent pure compounds. Finally, the study of surrogate fuels focuses attention on the fuel properties that are most important for determining engine efficiency, emissions, and other critical performance characteristics. In deciding which properties should be matched between the surrogate and the target fuel, the researcher incorporates hypotheses about the effects of specific fuel properties on in-cylinder mixing and combustion processes. If the resultant surrogate fuel fails to match the performance of the target fuel adequately, these underlying hypotheses must be reassessed and refined, ultimately leading to an improved understanding of the fundamental relationships between fuel properties and engine performance.

The development of a surrogate fuel model is a lengthy process [1-5]. Chemical kinetic models for each of the pure compounds in the surrogate fuel must be developed and validated by comparison to experimental data. A procedure needs to be identified to choose the relative concentration of each component in the surrogate to best reproduce the properties of the target fuel. The chemical kinetic mechanisms of the individual components need to be combined and 
important cross reactions between mechanisms included. The surrogate fuel model needs to be reduced in size so that it can be used in multidimensional computational fluid dynamic (CFD) models for simulating engine combustion. Finally, the surrogate fuel model needs to be validated by comparison with surrogate- and target-fuel experiments in practical combustion devices of interest.

Physical property models need to be developed for surrogate fuel components and their mixtures. These include models for density, volatility, surface tension, viscosity, thermal conductivity and species transport of the components and their mixtures. Measurements of these properties are also needed for validation of the model. These properties are needed to predict properly the fuel spray break-up, evaporation, and species transport that determine the reacting mixture temperature and species-concentration fields.

In this paper, the current status of diesel fuel surrogate development will be assessed. The review will build on previous reviews of experimental and chemical kinetic modeling of hydrocarbon fuels. In 2003, Simmie [6] reviewed the status of chemical kinetic models and experimental data for the oxidation of hydrocarbon fuels from each of the chemical classes (nalkanes, iso-alkanes, cycloalkanes, alkenes and aromatics). The progress towards the development of surrogate fuels for diesel was reviewed in the 2007 Farrell et al. paper [1]. Battin-Leclerc [7] recently reviewed in depth the progress in the development of detailed chemical kinetic mechanisms for gasoline and diesel surrogate fuels. The reader is referred to these excellent reviews for relevant work done prior to 2008. The current paper will focus on research progress from 2008 to the present, except for earlier studies that are relevant but omitted in previous reviews. In the current review, the status of chemical kinetic models of surrogate fuel components and their mixtures will be assessed. Next, chemical kinetic model reduction will be discussed, followed by an examination of progress toward models and measurements of physical properties of surrogate fuels. The paper concludes with recommendations for future work and a summary.

\section{CHEMICAL KINETIC MODELS FOR DIESEL FUEL COMPONENTS}

The relevant components for diesel fuel surrogates have been previously discussed and identified in [1], but they will be reviewed here. The primary chemical classes of the components in diesel fuel are n-alkanes, iso-alkanes, cycloalkanes, and aromatics (Fig. 1). Although the composition of diesel fuel is highly variable, there are some trends [1]: The carbon numbers of the components range from approximately C10 to C22. An average carbon number is 14 or 15 . The iso-alkanes are usually lightly branched with one or two side methyl groups. The cycloalkanes typically have one ring with multiple alkyl side chains. There are some two-ring cycloalkanes with alkyl side chains as well. The aromatics are usually one ring with multiple side chains. The average carbon number of the aromatics is about C12 as shown in the composition data in [1]. This carbon number is lower than the other chemical classes. There are also some two-ring aromatics with alkyl side chains. 


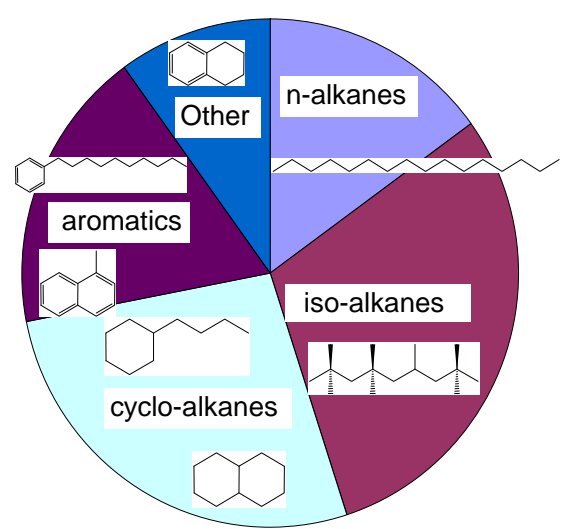

Figure 1. Relative amounts of various chemical classes in diesel fuel and possible chemical components to represent these chemical classes in a diesel surrogate fuel.

In the following sections, recent developments in chemical kinetic models and experiments for each chemical class will be discussed in turn.

\section{n-Alkanes}

There has been much recent progress on the development of chemical kinetic models for components relevant to diesel fuel. Most of the progress has been in the chemical class of nalkanes. Chemical kinetic detailed mechanisms for n-alkanes from n-C8 up to n-C16 have been developed $[8,9]$. Together with previous work $[10,11]$, this allows the simulation of all nalkanes up to C16. The mechanisms include low temperature chemistry, which is essential for investigating low temperature combustion strategies in diesel engines. Figure 2 shows a simulation of the ignition delay of large n-alkanes at 13 bar from low to high temperature [5]. The model predicts that all n-alkanes from n-C7 to n-C16 ignite with nearly the same ignition delay times within a factor of about 1.5. This trend was not seen in the simulations of [9], but was seen in the shock tube experiments of [12] discussed later. For C10 and C12 n-alkanes, there has been considerable progress reported in the literature. You et al. [13] developed a mechanism for n-dodecane and n-decane that is valid above $850 \mathrm{~K}$. It was validated by comparison to pyrolysis experiments in plug flow and jet stirred reactors, and by comparison to shock-tube ignition delay times and laminar flame speeds. This model has been further improved and validated, and is available at [14]. In other work, Zhang et al. [15-18] extended a high-temperature, n-heptane mechanism up to n-hexadecane with a focus on predicting the formation of the unsaturated soot-precursor species in premixed flames. 


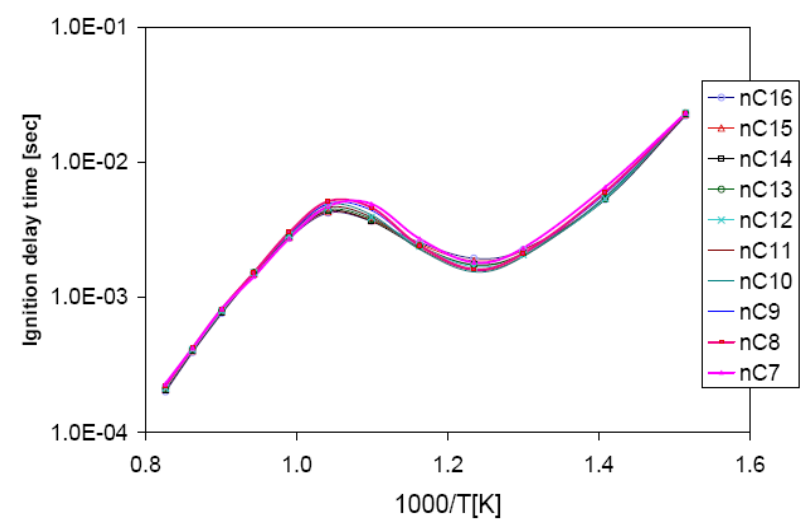

Figure 2. Ignition behavior of a series of large n-alkanes (stoichiometric fuel-air mixtures, initial pressure of 13.5 bar, temperatures from $650-1200 \mathrm{~K}$ ) [8].

There also has been considerable progress in acquiring experimental data for large n-alkanes. These experimental data are valuable for validating detailed chemical kinetic mechanisms and for gaining insight into the behavior of these fuels. Shen et al. [12] have recently obtained shock tube ignition data for a series of large n-alkanes up to C16. Their experiments were performed over a temperature range of 786-1396K, a pressure range of 9-58 atm and for equivalence ratios of $0.25,0.5$, and 1.0 . These conditions of pressure and temperature simulate conditions found in internal combustion engines. Experimental results in Figure 3 show that the measured ignition delay times are very similar for a series of large n-alkanes. The curves that encompass the data give about a factor of two variation in ignition delay times compared to a factor of 1.5 seen in the Westbrook et al. simulations (Fig. 2) and indicate a general trend for large n-alkanes. However, the experimental work does not cover the complete low temperature regime from 650-780K. In other work, Biet et al. [9] obtained experimental data for n-decane and an n-hexadecane/ndecane mixture in a jet stirred reactor at 1 atm over a range of temperatures from 550-1100K. Their detailed chemical kinetic model was able to reasonably reproduce their experimental data. In a subsequent paper on the same fuel mixture, Hakka et al. [19] were able to identify a much more complete spectrum of intermediate species including high-molecular weight alkenes, aldehydes, ketones and cyclic ethers in the jet stirred reactor.

Significant experimental validation data recently have become available in the lower molecular weight range of diesel (C10 and C12 n-alkanes) because this carbon range is also important for jet surrogate fuels, which have received considerable recent attention. Vasu et al. [20] measured shock tube ignition delay times and $\mathrm{OH}$ concentration histories for n-dodecane. Their experiments were performed over a temperature range of 727-1422K, a pressure range of 15-34 atm and for equivalence ratios of 0.5 and 1.0. Their experimental data for ignition delay times agree quite well with Shen et al. [12].

The shock tube studies above considered equivalence ratios up to 1 . There is a need to investigate equivalence ratios greater than 1.0 because diesel engine ignition occurs at equivalence ratios of about 2-4 under conventional diesel engine conditions [21]. This 
equivalence ratio range should be extended to the low end (about $\phi=0.3$ ) to explore new strategies of low temperature combustion in a diesel engine [22, 23]. Thus, a range of equivalence ratios from approximately 0.3 to 3 is needed for fundamental validation data relevant to diesel engine conditions. Such fuel-rich conditions may be challenging in a heated shock tube where adequate vaporization is difficult to achieve with high molecular weight fuels.

Davidson et al. [24] examined n-dodecane in their aerosol shock tube, which allows the investigation of ignition of high boiling point fuels without heating the shock tube. Although their experiments were at lower pressures (5.8 -6.7 atm) than other studies, they found similar trends for ignition delay with temperature as Vasu et al. when the usual $\mathrm{P}^{-1}$ pressure dependence was assumed. Zhukov et al. [25] examined the shock tube ignition of n-decane at high pressures up to $80 \mathrm{~atm}$ and temperatures ranging from $800-1300 \mathrm{~K}$ for stoichiometric and lean mixtures. The above experimental data were all taken at conditions relevant to internal combustion engines.

Kumar et al. [26] studied the ignition of n-decane in a rapid compression machine (RCM) at compressed-gas pressures of 7-30 bar, compressed gas temperatures of $635-770 \mathrm{~K}$ and equivalence ratios of 0.5 to 2.2. They found two-stage ignition behavior over the entire range of conditions that they investigated. Their measured ignition delay times agree with the shock tube ignition delay measurements of Pfahl et al. [27] at an equivalence ratio of 0.5, but are shorter than Pfahl et al. at near stoichiometric conditions. Discrepancies were identified between Kumar et al.'s measured ignition delay times and the predictions of two chemical kinetic models $[8,28]$. Kumar et al. [29] also measured the laminar flame speeds of n-decane and n-dodecane in a counterflow configuration at unburned reactant temperatures of $360-470 \mathrm{~K}$, equivalence ratio range of 0.7-1.4 and atmospheric conditions. Biet et al. [9] improved the automatic generation of a chemical kinetic mechanism for n-alkanes by improving the treatment of the consumption of primary products such as alkenes, aldehydes and cyclic ethers. They applied the mechanism to the simulation of their new experimental data for stoichiometric mixtures of n-decane and ndecane/n-hexadecane in a jet stirred reactor at 1 atm over a temperature range of 550 to $1100 \mathrm{~K}$. They also used the new chemical kinetic mechanism to simulate the experimental data of ndecane in a perfectly stirred reactor by Dagaut et al. [30] and n-dodecane in a flow reactor [31]. The agreement between the new chemical kinetic mechanism and measurements for the different experimental configurations and n-alkanes was reasonable. In a later study, Hakka et al. [19] measured a more complete set of intermediate products for n-decane and an n-decane/nhexadecane mixture in a jet stirred reactor at the same conditions.

For n-alkanes, more experimental data are needed to fill out the carbon range from C15 to C20. This has been a challenge because it is difficult keep these higher molecular weight fuels in the vapor phase in fundamental experimental devices such as shock tubes. Nevertheless, more experimental data are now available for large n-alkanes, and these additional data should be used to help further validate and develop chemical kinetic models. An additional need is for experimental validation data that include species typical in engines when exhaust gas 
recirculation (EGR) is employed. These species are water, carbon dioxide, carbon monoxide, nitric oxide, molecular nitrogen and others. A recent paper [32] has identified discrepancies between chemical kinetic model predictions and experimental measurements when EGR is included. The work focused on the effects of the EGR species water, carbon dioxide, and molecular nitrogen.
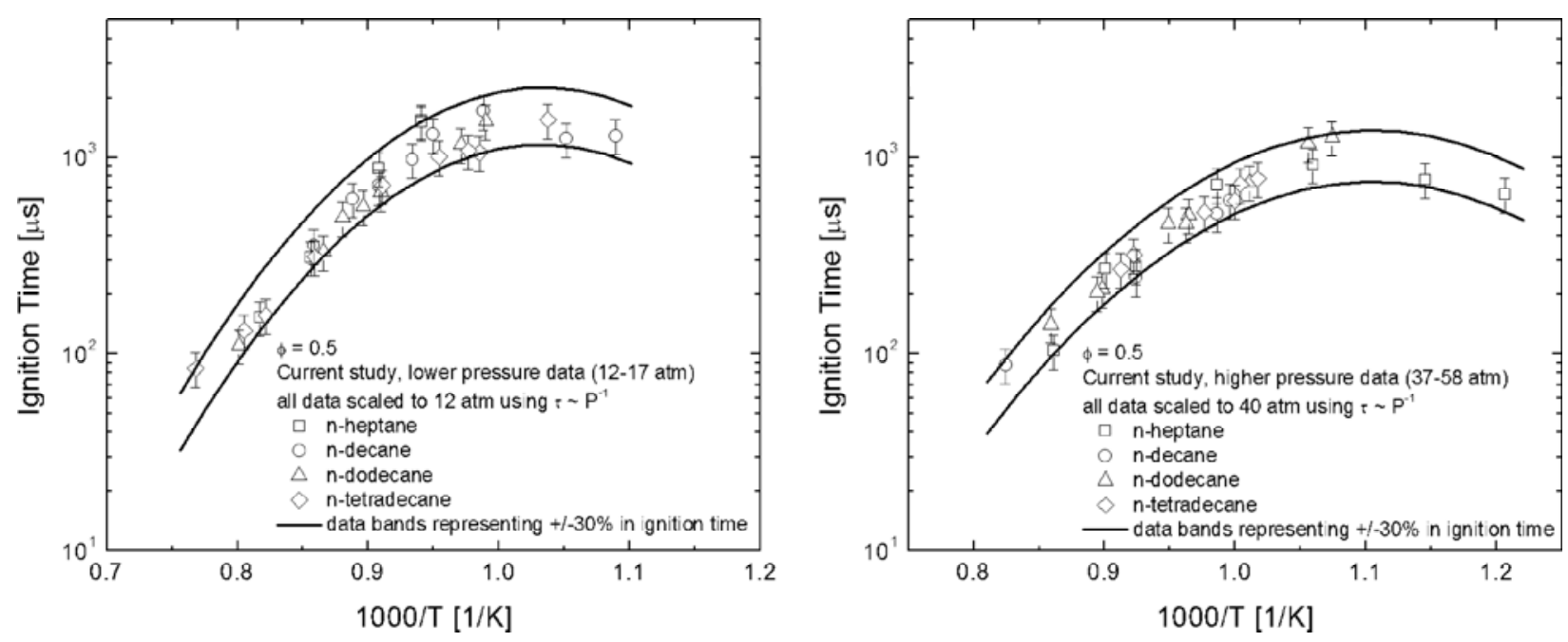

Figure 3. Experimentally measured ignition delay times for $\mathrm{C} 7, \mathrm{C10}, \mathrm{C12}$ and $\mathrm{C14}$ n-alkanes at an equivalence ratio of 0.5 [12]. Reprinted ("Adapted" or "in part") with permission from [12]. Copyright 2009 American Chemical Society.

\section{iso-Alkanes}

There has been significant progress in the area of iso-alkanes, particularly for iso-cetane (2,2,4,4,6,8,8-heptamethylnonane). Iso-cetane has 7 methyl branches, while most iso-alkanes in diesel fuel contain one or two methyl branches [1]. The effect of these additional methyl branches likely is reflected in the low cetane number of iso-cetane of 15 [33]. Iso-cetane has an assigned cetane number because it is a primary reference fuel for diesel. Primary reference fuels are used to rate diesel ignition properties through the cetane number test [34]. A low cetane number means a fuel component is relatively resistant to ignition in a diesel engine while a high cetane number indicates it is easily ignited. Compared to iso-cetane, lightly branched isoalkanes like 7,8-dimethyltetradecane and 9-methylheptadecane are more easily ignitable and have cetane numbers of 40 and 66, respectively [35]. Although iso-cetane's ignition properties are not representative of lightly branched iso-alkanes, its low reactivity can be used to balance high reactivity components, like n-alkanes, in a diesel surrogate. Because of its use as a primary reference fuel, iso-cetane is readily available to experimentalists in high purity at relatively low cost. It is also an iso-alkane that is in the middle of the carbon range for diesel fuel, C10 - C22, a feature which helps in matching the distillation curve of diesel.

Oehlschlaeger et al. [36] measured shock tube ignition delay times for iso-cetane at conditions relevant to diesel engines (temperatures from 953-1347K, pressures from 8-47 atm and for 
equivalence ratios of $0.5,1.0$ and 1.5). These measurements were compared to a newly developed chemical kinetic mechanism for iso-cetane based on a previous and successful model for iso-octane [37]. The computed and measured results showed good agreement. A similarity was found between the autoignition process of iso-cetane and iso-octane. The low reactivity of both fuels at these intermediate to high temperatures can be attributed to the production of isobutene which produces relatively stable 2-methyl-allyl radicals.

Dagaut et al. [38] investigated the oxidation of iso-cetane $/ \mathrm{O}_{2} / \mathrm{N}_{2}$ mixtures in a jet stirred reactor at $10 \mathrm{~atm}$ and equivalence ratios of $0.5,1.0$ and 1.5. They measured the species concentrations in the reactor over a temperature range from $770-1070 \mathrm{~K}$. Their results showed iso-butene as the major hydrocarbon intermediate. They simulated their results with two chemical kinetic models. One had lumped chemistry for the whole scheme [39]. The other used automatic generation to produce the mechanism [40]. It had detailed chemistry for the fuel, C0 and C1 species, with lumped chemistry for the remaining reactions. Neither detailed model included low temperature chemistry since none was observed with the highly-diluted mixtures used. The fully lumped model [39] was unable to satisfactorily reproduce the experimental data. The partially lumped model [40] simulated the fuel profiles very well, but predicted ethene instead of iso-butene as the major hydrocarbon intermediate.

Recently, Ranzi et al. [41] corrected the erroneous computed results reported in [38] that showed poor agreement of the lumped iso-cetane model compared to the stirred reactor experiments of iso-cetane [38]. The simulation error was due to convergence problems. Once the simulations were corrected, the agreement between the Milano model predictions and the stirred reactor measurements was reasonable.

There is still a considerable gap in knowledge for large iso-alkanes, particularly lightly-branched iso-alkanes that are more representative of diesel fuel components. Inclusion of these additional iso-alkanes would enable the development of a surrogate palette that more accurately captures the structure and properties of the iso-alkanes in market diesel fuels. With regard to physical properties, experimental and modeling characterization of a series of iso-alkanes may be helpful to properly represent the distillation curve of diesel fuel. Huber et al. [42] have found that isoalkanes need to be included in a surrogate to properly simulate the thermal conductivity of liquid diesel fuel.

\section{Cycloalkanes}

Cycloalkanes usually comprise less than $5 \%$ of diesel fuel derived from conventional crude-oil sources [1], but are much higher in alternative diesel fuel derived from oil-sands deposits [43]. The cycloalkanes in diesel usually have multiple, alkyl side chains [1]. Discussed below is recent progress in chemical kinetic models and experimental data, starting with C6 cycloalkanes and increasing in carbon number. 
There has been considerable progress on the development of chemical kinetic models for cyclohexane. Detailed chemical kinetic models for the oxidation of cyclohexane have been developed [44-46]. These models generally reproduce well the oxidation of cyclohexane under conditions in a stirred reactor and rapid compression machines [47, 48]. In other work, Zhang et al. [49] developed a chemical kinetic model for cyclohexane and compared their model predictions to experimentally measured intermediate products in a low-pressure, premixed flame [50]. They focused on the pathways that lead to benzene formation.

Recently, a more accurate description of important low temperature reactions for cyclohexane oxidation has become available [51]. These reactions involve the addition of molecular oxygen to cyclohexyl radicals and subsequent isomerization reactions including the temperature and pressure dependence of their rate constants. This new knowledge of the complex behavior of these rate constants will likely allow a more accurate description of the ignition behavior of cyclohexane over the wide temperature and pressure range found in a diesel engine.

Much new experimental data on cyclohexanes has recently become available. Mittal and Sung [52] investigated the ignition of methylcyclohexane in an RCM at equivalence ratios of 0.5, 1.0 and 1.5, pressures of 15 and 25 bar and over a compressed-gas temperature range of 680-905K. The chemical kinetic model of Pitz at al. [53] predicted the shape of the measured ignition times with temperature, but the predicted times were longer than the measured times (Fig. 4). A twostage ignition with a strong negative coefficient behavior was observed where the ignition delay increases with increasing temperature. Yang and Boehman [54] have studied the oxidation of cyclohexane and methylcyclohexane under motored engine conditions. They measured the concentration of intermediate products including cyclic ethers that are an indication of low temperature chemistry. They showed that a methyl group side chain on the ring (i.e., methylcyclohexane) enhances the reactivity of the fuel. Vasu et al. [55, 56] measured the ignition delay times of methylcyclohexane over a wide range of temperature and pressure (800$1550 \mathrm{~K}, 1-50 \mathrm{~atm}$, and $\phi=0.5-2.0)$. They also measured $\mathrm{OH}$ concentration histories to provide further validation targets for chemical kinetic models. The same Stanford research group also investigated the shock tube ignition of cyclohexane and cyclopentane over a range of conditions important for internal combustion engines (11-61 atm, 847-1379 K, and equivalence ratios of phi $=1.0,0.5$, and 0.25) [57]. They found that current models [44, 45] captured the general trends of their experimental data, but their predicted ignition delays were generally longer than those measured. 
(a) $P_{C}=25.5$ bar, Mix \#1, $\phi=1.0$

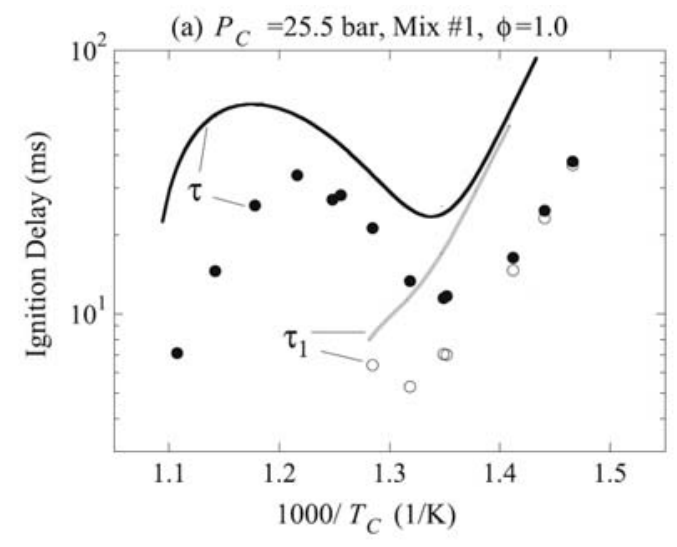

(b) $P_{C}=15.1$ bar, Mix \#2, $\phi=0.5$

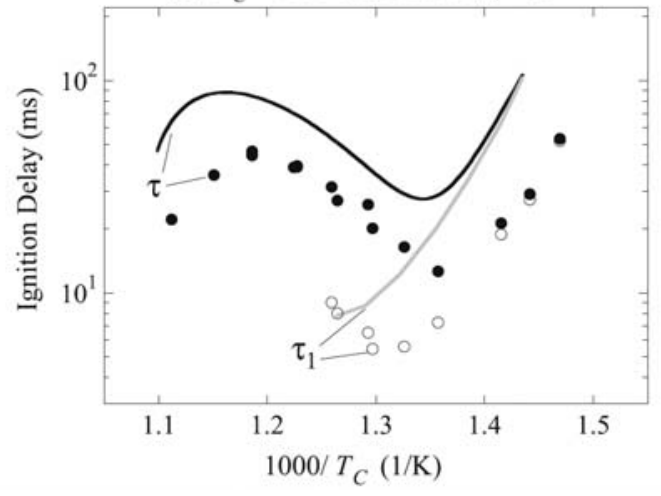

Figure 4. Comparison of experimental (symbols) and computed (lines) ignition delays of methylcyclohexane for (a) compressed gas pressure, $\mathrm{P}_{\mathrm{C}}=\mathbf{2 5 . 5} \mathrm{bar}$, Mix \#1 $\left(\mathrm{O}_{2} / \mathrm{N}_{2} / \mathrm{Ar}=10.5 / 12.25 / 71.75, \phi=1.0\right)$ and $(\mathrm{b}) \mathrm{P}_{\mathrm{C}}=15.1 \mathrm{bar}, \mathrm{Mix} \# 2\left(\mathrm{O}_{2} / \mathrm{N}_{2} / \mathrm{Ar}=7.16 / 16.35 / 71.75, \phi=\right.$ 0.5). Reprinted from [52] with permission from Elsevier.

Vanderover and Oehlschlaeger [58] investigated the shock tube ignition of methylcyclohexane and ethylcyclohexane over wide range of conditions (881-1319K, 11-70atm, $\phi=0.25,0.5,1.0)$. Their results showed the predicted ignition delay times from a recent chemical kinetic model [53] were too long at high pressure (50 atm). Sivaramakrishnan and Michael [59] experimentally measured rate constants for $\mathrm{OH}$ radicals with cyclohexane and methylcyclopentane. These rate constants will allow a more accurate description of the consumption reactions for cycloalkanes. In other work, Ciajolo et al. [60] measured the intermediate products of cyclohexane in a rich premixed flame and compared the results to their lumped chemical kinetic mechanism for cyclohexane. They found good agreement between the experimental and predicted profiles. They also added a soot model to the mechanism, but were not able to predict the early soot formation observed with cyclohexane. Bieleveld et al. [61] measured the autoignition temperatures and extinction conditions for methylcyclohexane. They found its ignition and extinction behavior to be between that of n-heptane and iso-octane.

For two-ring cycloalkanes, Oehlschlaeger et al. [62] measured the ignition delay times for a mixture of cis- and trans- decalin over a wide range of conditions (990-1300K, 9-15 atm and 35- 
$48 \mathrm{~atm}$, equivalence ratios of 0.5 and 1.0). They generated a lumped mechanism for decalin that contained high temperature chemistry only. The predicted ignition delay times compared reasonably well with the measured times. Yang and Boehman [63] investigated the oxidation of decalin (mixture of 62\% of trans- and 38\% cis- isomers) in a CFR octane-rating engine operated under motored engine conditions. They measured products in the exhaust of the engine at an engine speed of $600 \mathrm{rev} / \mathrm{min}$, equivalence ratio of 0.25 , intake temperature of $200^{\circ} \mathrm{C}$ and a compression ratio range of 4.5 to 12.2. Decalin exhibited significant low-temperature heat release in their motored engine. It reacted to aldehydes, small alkenes and CO through low temperature paths. Decalin also dehydrogenated to form hydronaphthalenes, naphthalene and tetralin. It underwent ring opening reactions. In other work, Chae and Violi [64] computed rate constants for the decomposition of decalin using density functional theory.

Although much progress has been made on cycloalkanes, more work is needed to cover the full carbon range of cycloalkanes. Single ring compounds, (C6 and C7 cycloalkanes) have been examined well. For C8 and C9, there is one study each [58] and [65], respectively. To our knowledge, there are no data available for one-ring cycloalkanes larger than C9. However, the full diesel range for cycloalkanes extends up to about C22 with an average of C14 or C15 [1]. Thus, there is a need to examine higher molecular weight compounds. These studies are challenging because fundamental investigations usually require maintaining these high boiling point compounds in the gas phase. Also, there is limited availability of such compounds at a reasonable price, even for relatively small quantities needed in fundamental combustion experiments.

\section{Mono-aromatics}

Aromatics comprise a large fraction of diesel (about 30-35\% by weight on average) [1]. Most of these aromatics are 1-ring with alkyl substitutions [1]. In the following section, developments in the chemical kinetic modeling and experimental investigation of alkyl substituted benzenes are discussed. (Benzene is not included because it is not present at any significant level in diesel fuel.)

There has been much progress in the development of chemical kinetic mechanisms for the only C7 aromatic, toluene. Sakai et al. [66] made many improvements in the treatment of different reaction classes in toluene. They compared computed ignition delay times to those experimentally measured in a shock tube [67, 68]. Mehl et al. [69, 70] made further improvements to the Sakai et al. mechanism. They were able to simulate well the experimentally measured ignition delay times of Mittal et al. [71] in a rapid compression machine and Shen et al. in a shock tube [72]. The simulations showed that the discrepancies between ignition delay times in the shock tube and rapid compression machine could be explained by heat losses in the RCM. The Shen et al. [72] shock tube experiments covered a wide range of conditions (1021$1400 \mathrm{~K}$, pressures of 10-61 atm, and equivalence ratios of 1.0, 0.5, and 0.25.) They did not observe early pressure rise during the ignition process for toluene reported by Davidson et al. 
[73], nor did the Mehl et al. model predict such pressure rise. Blanquart et al. [74] extended their chemical kinetic mechanism to include toluene. They obtained good agreement between predicted and measured shock tube ignition delay times at high temperature and laminar flame speeds at $1 \mathrm{~atm}$.

Shen et al. [75] studied the autoignition of the C8 aromatics (ortho-xylene, meta-xylene, paraxylene and ethylbenzene) in a shock tube over a wide range of conditions relevant to diesel engines (941-1408 K, 9-45 atm, and equivalence ratios of 5.0 and 1.0). Ethyl benzene was found to be the most reactive followed by the less reactive xylenes, ortho, meta and para. Ignition delay times for p-xylene matched up closely with their recent toluene measurements [72].

Roubaud et al. [76, 77] studied C9 aromatics in a RCM at compressed gas temperatures of 600 to $900 \mathrm{~K}$ and pressures of 12-15 atm. They examined the ignition of 1,2,3-trimethyl benzene, 1,2,4-trimethyl benzene, 1,3,5-trimethyl benzene and 2-ethyl toluene in stoichiometric, $\mathrm{O}_{2}$-inert mixtures. They found that 1,2,3-trimethyl benzene, 1,2,4-trimethyl benzene, and 2-ethyl-toluene ignited more easily than 1,3,5-trimethyl benzene. They attributed the easier ignition to the availability of ortho alkyl groups with their more easily transferable $\mathrm{H}$-atoms in the alkylbenzylperoxy radicals formed by these C9 aromatics. These internal H-atom transfers lead to chain branching and higher reactivity. Litzinger et al. [78] studied the oxidation of iso-propyl benzene in an atmospheric flow reactor at $1000 \mathrm{~K}$ and $1060 \mathrm{~K}$, and at equivalence ratios of 0.52 , 1.0 and 1.5. They determined the ratio of the abstraction rates of benzylic hydrogen atoms to primary hydrogen atoms in iso-propyl benzene to be approximately 6 to 1 . A detailed chemical kinetic model for 1,2,4-trimethyl benzene was developed by Bikas [79] and used by Peters and coworkers $[80,81]$ as a component in a kerosene surrogate fuel. Trimethylbenzenes also were studied in other work in binary mixtures with 1-methylnapththalene discussed below.

For C10 aromatics, Pousse et al. [82] developed a high temperature mechanism for nbutylbenzene. They compared computed results with experimental measurements of species concentrations from a low-pressure, lean, premixed, methane flame doped with n-butylbenzene and obtained satisfactory agreement.

\section{Naphthalenes}

There has not been a great deal of recent progress on naphthalenes. Mati et al. [83] measured the species concentrations for 1-methylnaphthalene oxidation in a (JSR) at 800-1421K, 1-10 atm and at $\phi=0.5-1.5$. They developed a chemical kinetic mechanism for 1-methylnaphthalene and compared the computed results to their JSR measurements and the shock tube ignition measurements of Pfahl et al. [27]. Bounaceur et al. [84] developed a chemical kinetic mechanism for 1-methylnaphthalene and validated it by comparison to experiments in a shock tube (900-1500K, 13 bar, stoichiometric) [85], flow reactor (1170K, $1 \mathrm{~atm}, \phi=.6,1.0,1.5)$ [86], and jet stirred reactor $(800-1100 \mathrm{~K}, 10 \mathrm{bar}$, stoichiometric mixtures). There is a need to obtain more experimental data on ignition delays for alkyl substituted naphthalenes in shock tubes and 
RCMs at conditions relevant to diesel engines (800-1200K, 10-50 atm, $\phi=0.5-3)$. A lower limit temperature of $800 \mathrm{~K}$ is listed here because these compounds will probably not ignite on the time scale of milliseconds below 860K, based on the experimental data of Pfahl et al. [27].

\section{Tetrahydronaphthalenes}

Yang and Boehman [63] investigated the oxidation of tetralin in a CFR octane-rating engine operated under motored engine conditions. They measured the products in the exhaust of the engine at an engine speed of $600 \mathrm{rev} / \mathrm{min}$, equivalence ratio of 0.25 , intake temperature of $200^{\circ} \mathrm{C}$ and a compression ratio range of 4.5 to 12.2 . Unlike the previously discussed decalin, tetralin exhibited little low temperature chemistry in their motored engine. Tetralin mainly dehydrogenated to form 1,2-dihydronaphthalene and naphthalene. Ring-opening reactions occur to a lesser extent for tetralin relative to decalin. No additional information could be found on the oxidation of tetrahydronaphthalenes in the peer-reviewed literature. However in his Ph.D. thesis, Wilk [87] studied the oxidation of mixtures of n-dodecane and tetralin in a constant volume vessel at 60 to 240 torr and 520-620K. He added 5, 10 and 20\% tetralin to n-dodecane. He found the addition of tetralin to n-dodecane increased the pressure where the onset of cool flames is observed for temperatures below 530K. Above 530K, the addition of tetralin has little effect on the pressure where the onset of cool flames is seen. He also found that the addition of tetralin increased the induction period before cool flames are observed. This effect was nonlinear with the $5 \%$ addition of tetralin having the largest effect and subsequent addition of tetralin having proportionally smaller effect.

\section{SURROGATE MIXTURES}

Surrogate mixtures are mixtures of components used to represent the target, real fuel whose behavior one desires to model. The behavior of multicomponent fuels is more complicated than single component fuels because species produced from one component can react with species from another component. These interactions often manifest themselves in the observed ignition delay times, flame speeds and other combustion characteristics of surrogate mixtures. The interactions need to be quantified by experiments and correctly simulated by chemical kinetic models so that combustion behavior of practical fuels can be accurately predicted. In the discussion below, recent research on surrogate mixtures is reviewed starting with binary mixtures and then progressing to more complex mixtures.

Honnet et al. [80] investigated the Aachen surrogate of $80 \%$ n-decane and 20\% 1,2,4trimethylbenzene used to represent JP-8 jet fuel. They performed experiments in a laminar, counterflow, diffusion-flame. They found that the Aachen surrogate had similar ignition and extinction characteristics, and measured soot concentrations compared to JP-8 in the counterflow flame. They developed a detailed chemical kinetic model to describe the Aachen surrogate and validated it over a wide range of conditions. The predictions of the chemical kinetic model compared fairly well with their experimental measurements of ignition and extinction. 
Lemaire et al. [88] have investigated the IDEA surrogate diesel fuel [89] which consists of 70\% n-decane and 30\% 1-methyl naphthalene (1-MN) and compared it to a low-sulfur diesel that contained $8 \%$ by volume esters. They investigated these fuels in an atmospheric pressure, flat flame burner with an injector tube in the center that nebulizes the liquid fuel and produces an aerosol. The flat flame burner is supplied with methane-air mixture. Based on laser induced incandescence (LII) of the soot and laser induced fluorescence of the PAH (polycyclic aromatic hydrocarbons desorbed from the soot), they found that the IDEA fuel produced too much soot and PAHs compared to the low sulfur diesel fuel. Therefore, they reduced the amount of 1-MN in the surrogate fuel. To determine the amount of 1-MN, they used the threshold soot index (TSI) and matched the TSI of the surrogate and the diesel fuel. A surrogate with 20\% 1-MN (instead of previously used 30\%) matched the TSI of the diesel fuel. This new surrogate also matched the measured LII and PAH levels of the diesel fuel quite well (Fig. 5). This work supports the use of TSI to match the sooting behavior of the surrogate with the target real fuel [90-92], but it is not clear that fuel-induced changes in TSI quantitatively indicate the magnitude of fuel-induced changes in exhaust particulate matter (PM), soot, or smoke emissions from a diesel engine. When the researchers examined the PAHs absorbed on the soot, they found that the molecular weight distribution of the measured PAHs from the surrogate was narrower than the distribution from the diesel. Also note that the oxygenate content of the ester components in the low sulfur fuel likely reduced the levels of soot and PAH below those produced by a conventional diesel. This means that although the new surrogate works best compared to this diesel containing esters, the standard IDEA surrogate with 30\% 1-MN may still work best in comparison to conventional diesel fuel. However, the findings of this work concerning how to match a surrogate fuel to a target real fuel are important.

Kook and Pickett [93] investigated a surrogate of 23\% m-xylene and 77\% n-dodecane and compared it to a conventional jet fuel in a high-pressure, high-temperature combustion vessel used to simulate conditions in a diesel engine. Using planar LII, they showed that the surrogate fuel sooted more than the conventional jet fuel. They attributed this behavior to the surrogate fuel having a higher aromatic content than conventional jet fuel. Natelson et al. [94] tested the reactivity of a surrogate containing 50\% n-decane / 25\% n-butylbenzene / 25\% nbutylcyclohexane in a pressurized flow reactor at 8 bar. This surrogate matches the maximum aromatic content allowed in jet fuel and the H/C ratio in a US average JP-8 jet fuel [3]. They also tested a surrogate containing 33\% n-decane / 33\% n-butylbenzene / 33\% nbutylcyclohexane which was proposed to match diesel fuel properties. They used the amount of $\mathrm{CO}$ formation in the flow reactor as a measure of reactivity of the surrogate and the target fuels. They found these surrogates to be more reactive than the jet and diesel fuels they were designed to match. 

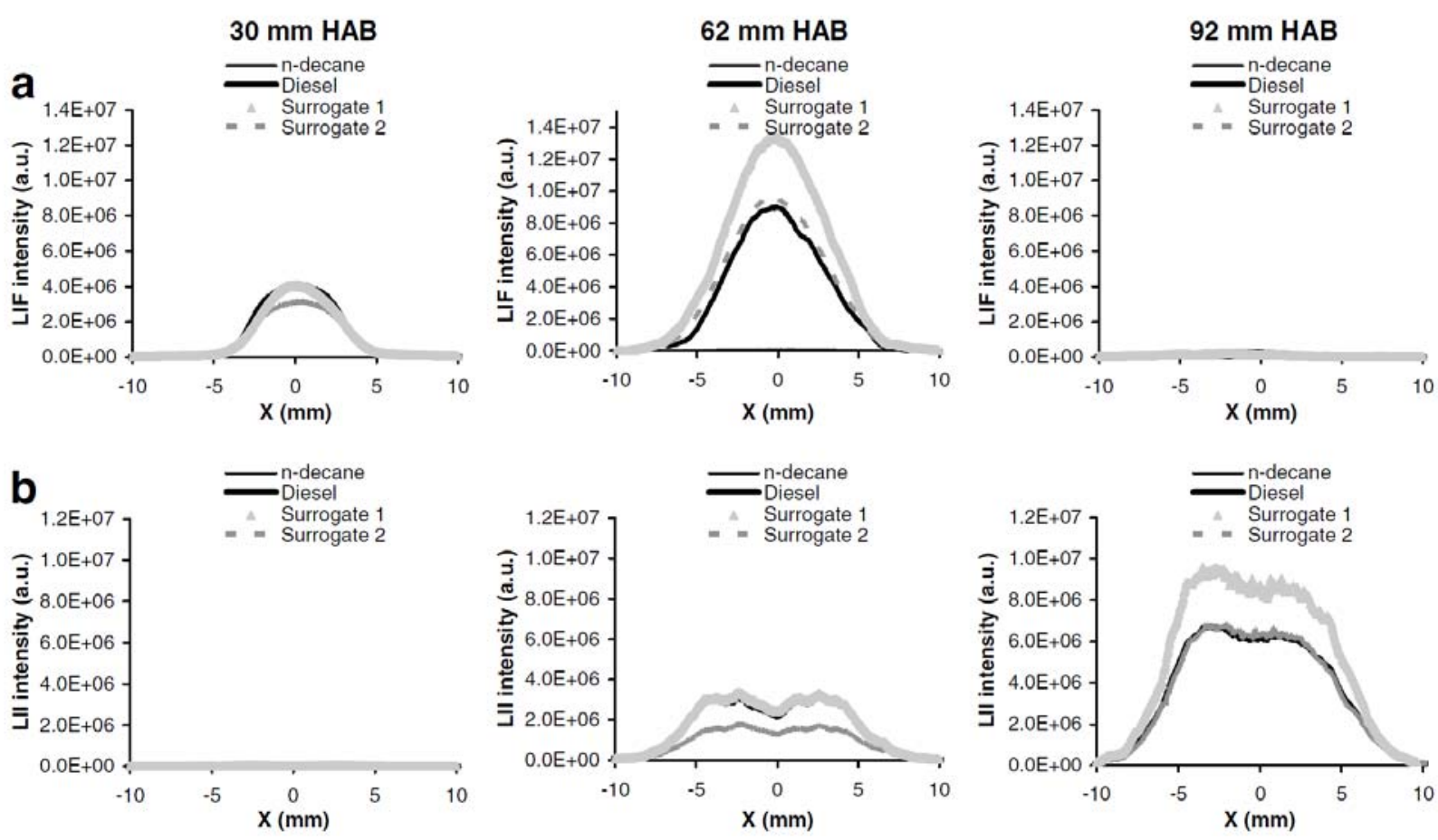

Figure 5. Radial profiles of (a) laser-induced fluorescence of PAH and (b) laser-induced incandescence (LII) of soot particles obtained at different heights above the burner (HAB) in each flame. Surrogate 1 is original IDEA fuel of 30\% 1-MN/70\% n-decane. Surrogate 2 is new proposed surrogate of $20 \%$ 1-MN/80\% n-decane. N-decane signals are very weak indicating near zero soot on this plot. The triangles and dashed line sometimes appear as solid lines. Reprinted from [88] with permission from Elsevier.

In a series of studies from the same research group, Douce et al. [95] and Mathieu et al. [96] studied the sooting tendencies of diesel surrogate components and a diesel surrogate mixture in a high temperature shock tube. In their first study, Douce et al. [95] examined the fuel components n-hexadecane, toluene, n-heptylbenzene, and 1-methyl naphthalene at temperatures of 1300 and $2700 \mathrm{~K}$, pressure of $2-18$ atm, under pyrolysis (without oxygen) and for two equivalence ratios (5 and 18). They measured the evolution of soot particles using laser light extinction. They found that 1-methyl naphthalene had the shortest soot induction times under pyrolytic conditions, followed by toluene and n-heptylbenzene. N-hexadecane had the longest soot induction time. Soot induction time is an indication of how rapidly a fuel will form soot. They also measured soot yields which is the fraction of carbon in the fuel that forms soot. Under pyrolysis, 1-methyl naphthalene had the greatest soot yield (Fig. 6). At an equivalence ratio of 5 (which is probably more relevant to diesel combustion than pyrolysis) 1-methyl naphthalene had the largest soot yield, twice that of toluene. 


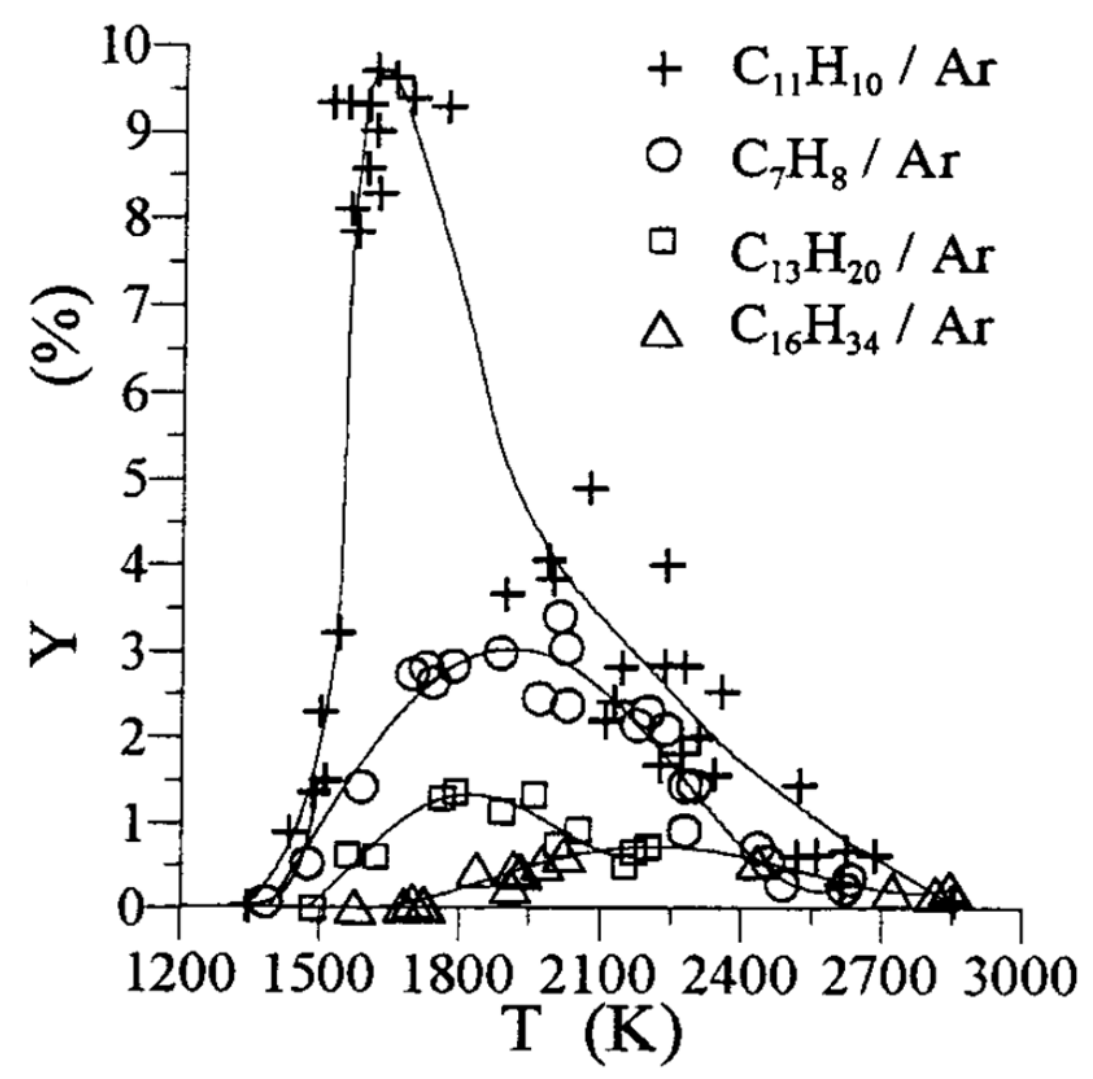

Figure 6. Soot yields from the pyrolysis of 1-methyl naphthalene, toluene, n-heptylbenzene and nhexadecane at pressures of $10-18$ atm and temperatures of $1350-2850 \mathrm{~K}$ in a shock tube. Reprinted from [95] with permission from Elsevier.

In the second study from the same group and using the same experimental apparatus, Mathieu et al. [96] examined n-propylcyclohexane (PCH), n-butylbenzene (BBZ), 2,2,4,4,6,8,8heptamethylnonane (7MN) and a diesel fuel surrogate mixture of $39 \% \mathrm{PCH}+28 \% \mathrm{BBZ}+33 \%$ $7 \mathrm{MN}$ by mass. Soot formation was investigated at temperatures of $1460-2570 \mathrm{~K}$, pressures of $11-18 \mathrm{~atm}$ and under oxidative (equivalence ratios of 5 and 15) and pyrolytic conditions. Of the fuel components considered in the second study, they found that the soot induction times under pyrolytic conditions were shortest for n-butyl benzene, indicating it forms soot most rapidly. The next shortest induction time was the diesel surrogate mixture, followed by n-propyl benzene, and heptamethylnonane. Fig. 7 summarizes the results of both studies with 1-methyl naphthalene having the shortest soot induction times (not shown, but its induction times are slightly shorter than toluene) and n-propylcyclohexane having the longest time. It is somewhat surprising that a cycloalkane (n-propylcyclohexane) would have a longer soot induction time than an n-alkane (n-hexadecane), because literature studies indicate that cycloalkanes have higher particulate-matter formation tendencies (e.g. soot) than n-alkanes in diesel engines [97]. Mathieu et al. found further that n-butyl benzene produced larger soot yields under pyrolytic conditions than the other fuel components and diesel surrogate mixture considered. At an equivalence ratio of 5 (which was probably the equivalence ratio most relevant to diesel 
conditions), n-butylbenzene has the largest soot yield and n-propylcyclohexane is nearly as high. The diesel surrogate and heptamethylnonane yielded much less soot in comparison. It is interesting that, although n-propylcyclohexane is slow to start producing soot, it yields soot abundantly after its long induction period. This indicates that both the soot induction period and soot yield are important indicators of sooting tendencies of fuels.

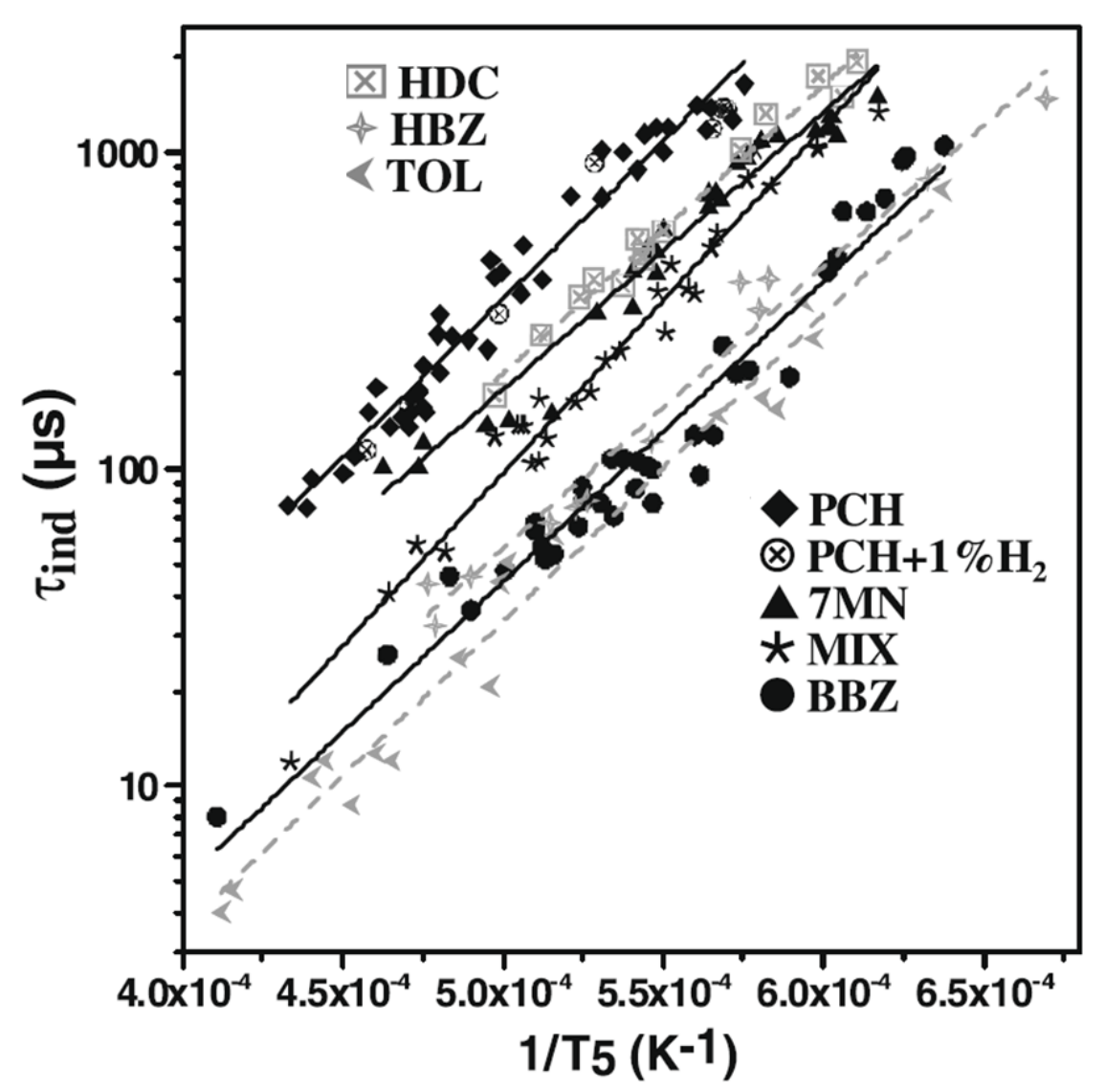

Figure 7. Soot induction times for n-propylcyclohexane (PCH), n-butylbenzene (BBZ), 2,2,4,4,6,8,8-heptamethylnonane (7MN) and a diesel fuel surrogate mixture (MIX) of 39\% PCH + $28 \%$ BBZ $+33 \% 7 \mathrm{MN}$ by mass [96]. Toluene (TOL), n-heptyl benzene (HBZ) and n-hexadecane (HDC) are from [95]. Reprinted from [96] with permission from Elsevier.

Steil et al. [98] found that modeling predictions for a surrogate mixture of $70 \%$ n-decane / $30 \%$ propylbenzene did not well represent experiments on shock tube ignition of kerosene.

Mati et al. [99] compared computed results of a five component mixture model with experimental measurements using a blended, synthetic diesel fuel in a jet stirred reactor (JSR) ( $\mathrm{T}=800-1400 \mathrm{~K}, \phi=0.5-2, \mathrm{P}=1 \mathrm{and} 10 \mathrm{~atm}$ ). In the experiments, gas samples were extracted from the JSR with a fused silica probe and analyzed online and offline by gas chromatography with a flame ionization detector and mass spectrometry. Species profiles of some of the measured species are shown in Fig. 8. The amounts of the five components $(23.5 \% \mathrm{n}$ - 
hexadecane, 19\% iso-octane, 26.9\% n-propylcyclohexane, 22.9\% n-propylbenzene and 7.7\% 1methylnaphthalene) used in the chemical kinetic model were chosen to match the amount of the various chemical classes in the synthetic diesel fuel (n-alkanes, iso-alkanes, cyclo-alkanes, alkyl benzenes and two-ring aromatics). The reactivity of the synthetic diesel fuel, based on the CO and $\mathrm{O}_{2}$ profiles, was well reproduced by the surrogate model at $10 \mathrm{~atm}$ for the stoichiometric and fuel-rich case (Fig. 8), but not at 1 atm. The comparison of the predicted and measured intermediate species profiles in the JSR was similarly much better at $10 \mathrm{~atm}$ than at $1 \mathrm{~atm}$. For the best comparisons (e.g., Fig. 8), the surrogate model was able to reasonably match many hydrocarbon intermediates and $\mathrm{CO}$, but not $\mathrm{CO}_{2}$. Because of poor agreement at $1 \mathrm{~atm}$, further work needs to be done to investigate the effect of pressure in the experimental results and model simulations. The comparison of the experimental and modeling results seems to substantiate that $\mathrm{CO}$ is a good measure of agreement in fuel reactivity between the model and experiment. This is the same method of measuring fuel reactivity used by the Drexel group in their high-pressure flow reactor [94]. When the comparison between the experimental and predicted CO was poor, the agreement of the rest of the species profiles was generally poor.

Myong et al. [100] experimentally investigated the injection of a diesel surrogate into a constant volume vessel filled with argon at a temperature of $400-700 \mathrm{~K}$ and a density of $5-20 \mathrm{~kg} / \mathrm{m}^{3}$. A common rail fuel injector was used. They found that the high-boiling point component of the diesel surrogate controls liquid phase length of the evaporating spray. In a later paper [101], they found that evaporation of the surrogate fuel is promoted by addition of a low boiling point component because the saturated-vapor pressure line of the high boiling point component shifts to a lower temperature in the two-phase region. 

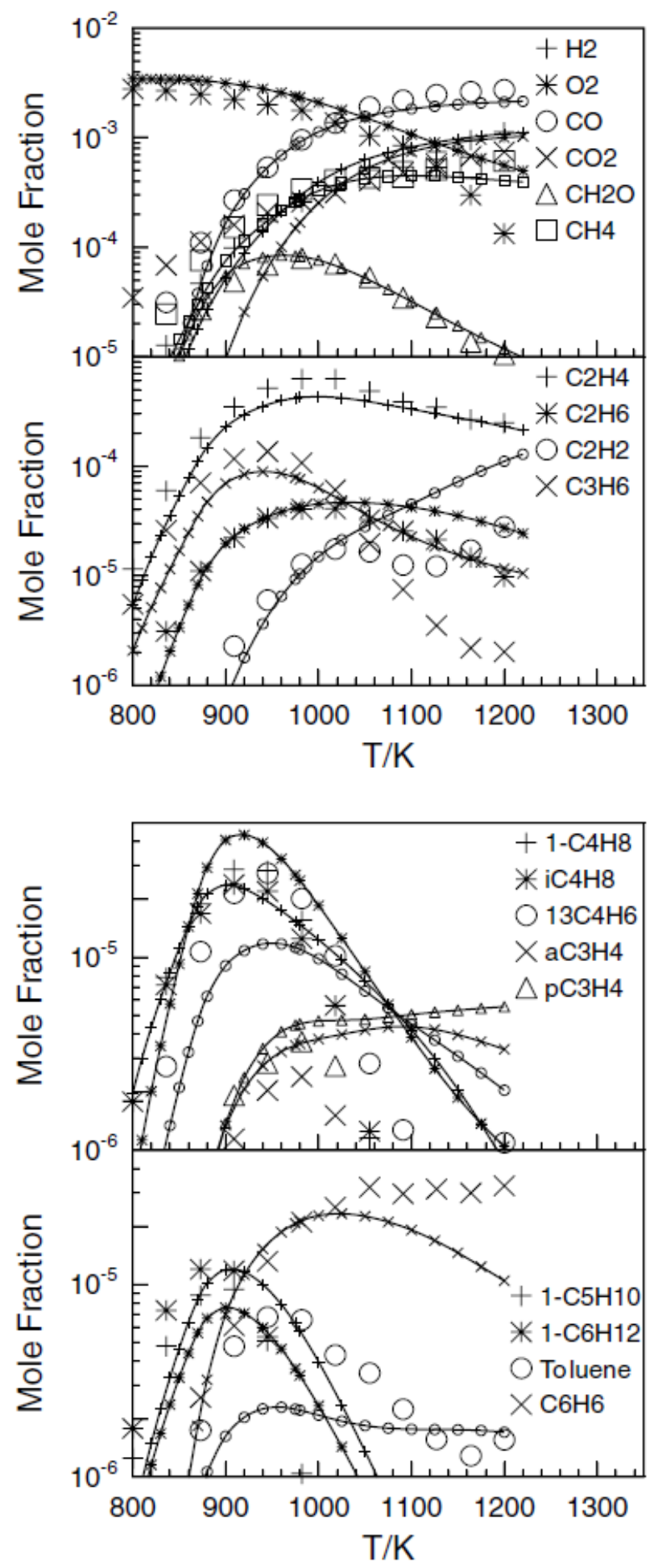

Figure 8. Comparison of a surrogate diesel model and synthetic diesel fuel experiments in a jet stirred reactor at $10 \mathrm{~atm}$ and $\phi=2$ (diesel, $0.05 \% ; \mathrm{O}_{2}, 0.345 \% ; \mathrm{N}_{2}, 99.6 \%$; residence time $\left.=0.5 \mathrm{~s}\right)$ Reprinted from [99] with permission from Elsevier.

In future work on surrogate fuels for diesel, surrogates need to be investigated that contain components that are more representative of the carbon range in diesel fuel (C10 to C22) [1]. 
There is a lack of representative components on the high end of the carbon range. Also, isoalkanes need to be added to the surrogate in the appropriate carbon range.

\section{REDUCTION OF DETAILED CHEMICAL KINETIC MECHANISMS}

There are many ways to reduce the computational costs of including fuel chemistry in reacting flow models. The most obvious way is to reduce the number of species and reactions in the mechanism, while maintaining the accuracy required for a given application [102, 103]. This reduction can be done by creating skeletal mechanisms and by lumping of species [104]. Skeletal mechanisms can be formed by a variety of methods including directed relational graph [105] and reaction flow analysis [106]. Further computational gains can be made by accounting for species that are in steady state [107] or partial equilibrium. An alternative to reducing the size of the detailed mechanism is to save computational time by pre-calculating the chemistry and using table lookups [108]. Mechanism reduction can be done "on the fly" during a reacting flow calculation, so that much smaller mechanisms can be used at different times and locations on the computational grid [109, 110]. There are other ways to reduce computational times. The computational efficiency of chemistry solvers can be improved [111]. The chemistry can be solved on a coarser computational grid than the flow dynamics, as is done in multizone homogeneous charge compression ignition (HCCI) engine calculations, which resulted in large computational speed-ups [112]. These methods and others have been reviewed recently by Lu and Law [113].

There has been much recent work on how to reduce chemical kinetic mechanisms and their associated computational costs. Lu and Law and co-workers have a series of papers on the directed-relational graph (DRG) method for mechanism reduction and stiffness removal for further computational cost reduction [113-115]. After performing DRG, lumping, quasi steadystate analysis (QSSA) and stiffness removal, they reduced a 561-species and 2539-reaction nheptane mechanism [10] to 52 species and 48 global reactions, while maintaining accuracy on target calculations for extinction in a perfectly-stirred reactor and constant-pressure ignition over a wide range of temperature and pressure [113] (Fig. 9). Prager et al. [116] also reduced Curran et al.'s n-heptane mechanism, but used the method of computational singular perturbation (CSP) [117]. They got good agreement for n-heptane premixed flames over a range of equivalence ratios and pressures. They were able to reduce the n-heptane mechanism to 66 species and 326 reactions. Neimeyer et al. [103] combined the DRG method with sensitivity analysis and errorpropagation to reduce an n-decane mechanism of 940 species and 3887 reactions to a skeletal mechanism containing of 211 species and 794 reactions. Pepiot-Desjardins and Pitsch [118] also used the DRG method and developed an approach to reduce a mechanism based on prediction of a series of targets, like ignition delay time, with a user-defined error tolerance. Sun et al. [102] have developed a direct path flux analysis method for generating skeletal mechanisms and found greater accuracy for a similar reduction in number of species than the DRG method over a wide range of pressures and temperatures. 
Hughes et al. [107] reduced an n-heptane mechanism of 358 species and 2411 reactions created by EXGAS [40] to a skeletal mechanism. Using QSSA, they further reduced the mechanism to 81 species and 341 reactions while retaining accurate reproduction of low and high temperature chemistry of the detailed reaction mechanism.

Nagy and Turányi [119] have developed an approach where strongly connected sets of species in a detailed mechanism are identified and added to a test mechanism in sequential steps, while checking for errors by comparison with simulations using the fully detailed model. Multiple test mechanisms are developed. The test mechanism with the smallest error and least CPU requirement is selected. They reduced a surrogate fuel mechanism with 345 species and 6874 reactions to 47 species and 246 reactions and obtained a computational speedup of 116 times in a zero-dimensional, methane-air, homogeneous reaction problem.

Chen and Tham [120] developed a more efficient method to solve for quasi steady-state (QSS) species in reduced chemical kinetic mechanisms. They identify QSS species that are strongly coupled and solve for them separately using a fixed point iteration and matrix inversion method. They saw speed-ups of a factor of 20 for a primary reference fuel mechanism (n-heptane and isooctane) with 101 regular species and 251 quasi-steady state species.

Janbozorgi et al. [121] used the rate-controlled constrained-equilibrium (RCCE) method to obtain faster chemistry solutions and tested it for the case of methane oxidation. The RCCE method was first developed in 1981 by Keck and Gillespie [122]. It is based on the principle that slow reactions impose constraints on the chemical system and control the rate at which the system relaxes to chemical equilibrium, while fast reactions equilibrate the system to the constraints imposed by slow reactions [121]. By using 12 constraints, they were able to reduce the number of reactions from 133 to 20 in RCCE calculations. Rigopoulos et al. [123] combined the RCCE method with the level of importance (LOI) method which is related to the CSP method and uses time scale analysis to determine which species must be retained in the mechanism. They obtained a combined speed up of over a factor of 10 for a propane mechanism with 117 species and 665 reactions in a laminar flame calculation. König and Mauss [124] have developed an on-demand, intrinsic low dimensional manifold (ILDM) method to reduce the computational requirements of detailed chemical kinetic mechanisms when calculating chemically reacting flows. Normally, the ILDM method requires the calculations of an ILDM table that covers the whole state space that is expected to be accessed by the computation. In the on-demand scheme, only the part of the ILDM table that is needed is generated "on the fly" during a reacting flow simulation. For a laminar flame calculation for syngas $\left(\mathrm{H}_{2} / \mathrm{CO}\right)$, they saw an $82 \%$ savings in computer memory storage using the on-demand scheme compared to the usual method of precalculating the ILDM table ahead of time.

Oluwole et al. [125] have developed a method that determines the range of validity (pressure, temperature and equivalence ratio) for a given reduced mechanism. 
Another way to reduce computational costs associated with chemical kinetic models in CFD calculations is to reduce the number of zones for which chemistry has to be solved in the computational domain. This is an attractive method because it reduces the total computational resources required for solution of the chemistry without the user having to devote effort in reducing the size of the chemical kinetic mechanism. Aceves et al. [126] first proposed such a method to reduce computational costs in HCCI engine calculations. Recently, Goldin et al. [127] developed a cell agglomeration (CA) technique that combines computational zones that have similar species compositions and reduces the number of zones for the chemistry solver. They saw speed-ups of 2 to 11 compared to runs without the CA method in a 2-D premixed flame and an axisymmetric, partially-premixed, engine simulation with methane as the fuel. The error tolerances chosen for these runs varied from 1 to $10 \%$.

An additional way to reduce the number of zones in which the chemistry has to be solved is adaptive mesh refinement (AMR) [128-130]. This method reduces the total number of zones or mesh cells in the entire computational grid by placing more zones in regions of high activity. The domain is first coarsely gridded with mesh cells. As a region of the mesh develops more activity and gradients, these coarse mesh cells are refined by dividing each mesh cell into smaller cells. As the gradients are reduced and a region becomes more homogeneous, the refinement of the mesh can be removed. Therefore, the total number of mesh cells in which the chemistry has to be solved is reduced because of the use of a course grid where refinement is only added as needed and removed when no longer needed. The criteria used to specify where more zones are added or removed are defined by the user or the computational code. For example, Day et al. [131] used criteria of high concentration of hydrogen peroxide $\left(\mathrm{H}_{2} \mathrm{O}_{2}\right)$ and high magnitudes of the fluid vorticity to specify the location of mesh refinement in a two-dimensional, hydrogen flame. Most of the effort in AMR has been on one- or two-dimensional meshes, although some work has been done on 3-D meshes [132, 133]. Additional work needs to be done to develop reliable algorithms for 3-D meshes needed for CFD calculations in internal combustion engines. When reliable and tested algorithms become available, this will be a very attractive approach because it can be automated, without much user involvement.

Liang et al. [110] used a dynamic adaptive chemistry strategy to reduce the chemistry "on the fly” in a reacting flow calculation. For a zero-dimensional, single-zone, HCCI engine calculation, they obtained a 70-fold CPU time reduction with a 1099 species mechanism of a gasoline surrogate fuel. He et al. [134] also used an "on the fly" reduction approach that consisted of chemical flux analysis and dynamic generation of reduced mechanisms. They saw a speed-up of a factor of 40 for a detailed chemical kinetic mechanism for n-pentane [10] with 385 species and 1895 reactions when simulating a computationally intensive calculation of a pairwise mixing stirred reactor. Singer and Green [135] developed an adaptive orthogonal decomposition method to solve the reaction-diffusion equation in reacting flow problems. The method allows a reduction in the number of equations that govern the combustion chemistry. For a one- 
dimensional, methane-air, premixed, laminar flame, they saw a speedup of 3.5 times in the reacting flow computation using GRIMech 3.0 [136].

It is difficult to determine the best methods to reduce detailed chemical kinetic mechanisms and their associated computational costs. Combined techniques, as promoted by Lu and Law [113], are likely to be a successful approach and used in future work. It is also likely that improvements in the numerical solvers $[111,135]$ will be combined with mechanism reduction techniques. Techniques such as CSP and principle component analysis may be more useful as tools to interrogate reaction mechanisms and to determine the controlling rate processes [137], than as mechanism reduction tools. For example, Lu et al. [138] used CSP analysis to define an explosive index (EI) for each species. EI is the normalized magnitude of an explosive mode which is associated with a positive eigenvalue in the Jacobian. The magnitude of the explosive index can be used in an ignition calculation to identify important species that lead to ignition. Another way to reduce computational costs is speeding up the chemistry solvers because it does not require the user to devote the time and effort to reduce the size of the mechanism. A faster chemistry solver called a sparse matrix solver was recently included in Chemkin [139]. In the long term, "on the fly reduction” likely will be employed because the reduced mechanisms produced need not be valid over the whole solution domain with this method, leading to greater mechanism reduction and computational speedups. Also "on the fly" methods do not require user time in performing lengthy mechanism reduction calculations. 


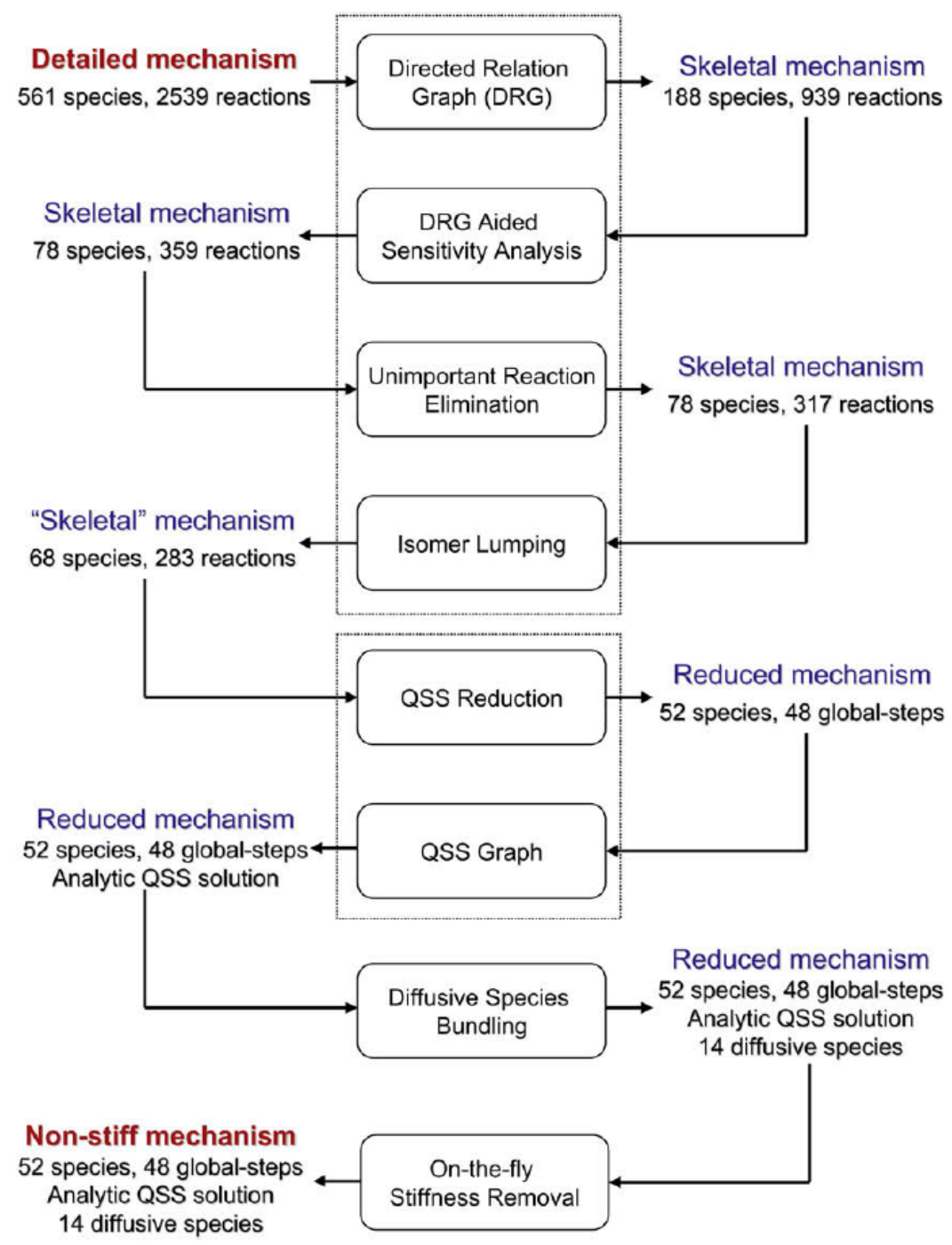

Figure 9. Flow chart of the integrated reduction procedure for an n-heptane mechanism. Reprinted from [113] with permission from Elsevier.

\section{SELECTION OF SURROGATE MIXTURES TO REPRESENT DIESEL FUEL}

Once a palette of surrogate compounds is available, a procedure is needed to select the surrogate compounds and their amounts that will be included in a surrogate fuel. Various procedures have been examined and discussed in the literature [4, 5, 90, 140].

Zhang et al. [140] matched chemical composition of a surrogate fuel to the target practical fuel (JP-8, a common aviation fuel) by using nuclear magnetic resonance (NMR) analysis. They tried to match as closely as possible the relative amounts of each type of carbon atom identified by NMR in the surrogate and the target fuels. The types of carbon atoms identified included those bonded to primary, secondary and tertiary $\mathrm{H}$ atoms. Other types of carbon atoms considered were aromatic carbons bonded to an $\mathrm{H}$ atom or to a carbon substitute. Carbons attached to 
bridges across cyclic compounds were identified, as well as additional types of carbon atoms. Finally, an attempt was made to match the relative amounts of eight types of NMR-classified carbon atoms in the surrogate and the target fuel.

Colket et al. [90] discussed the combustion and physical properties that are important to match between a surrogate fuel and a target practical fuel. In the case of jet fuel, they stated that H/C ratio, amount of each chemical class (e.g. aromatics), heat of combustion, smoke point [91], viscosity and distillation curve were the most important properties to match. Instead of smoke point, threshold sooting index (TSI) [92] and yield sooting index [141] could alternatively be used for accessing the sooting propensity of the fuel. To match chemical composition, they suggested NMR analysis [140]. They indicated that the above properties can be estimated using the proposed composition of the surrogate. They outlined an approach for making these property estimations.

Dryer et al. [5] presented a method for specifying a surrogate fuel composition for jet fuel. They advocated matching the following properties in the surrogate and the target jet fuel: $\mathrm{C} / \mathrm{H}$ ratio, threshold sooting index (TSI), and cetane number. They stated that is important to match the $\mathrm{C} / \mathrm{H}$ ratio because it affects surrogate properties such as flame temperature, heat of reaction, flame speed, and local air/fuel stoichiometric location. In addition, $\mathrm{C} / \mathrm{H}$ ratio of the surrogate fuel affects the total air/fuel flow rates through a combustion device. They recommend using cetane number to match the ignition properties of the surrogate and jet fuel. Because of its ease of use, repeatability and accuracy, they also recommend using the IQT test [142] to determine cetane numbers for surrogate components, their mixtures and the target fuel.

Puduppakkam et al. [4] presented an approach where the component type and quantity in a surrogate fuel were determined by matching a number of properties of the target fuel. The proposed properties to be matched in the target fuel were lower heating value, $\mathrm{C} / \mathrm{H}$ ratio, distillation curve, and ignition quality. Since the target fuel in this case was gasoline, octane number was used as a measure of ignition quality. For diesel, cetane number can be used. The distillation curve is matched by matching the T10, T50 and T90 points, where T10 is the mixture boiling temperature where $10 \%$ of the liquid fuel volume is distilled. An iterative approach was used to determine the composition of the surrogate (as shown in Fig. 10).

In the future work on surrogate fuels, many of the above characteristic properties will likely be used to specify surrogates for practical fuels, including NMR to specify chemical composition, $\mathrm{C} / \mathrm{H}$ ratio to ensure proper flame temperatures, cetane number for ignition quality, threshold sooting index for sooting propensity, and a method for specifying a proper distillation curve. However, these properties are global indicators for an initial selection of a surrogate fuel. Further refinement of the surrogate selection can be made by comparing the surrogate and target fuel behavior in fundamental laboratory devices like shock tubes, flow reactors, jet stirred reactors, rapid compression machines, and premixed and non-premixed flames. For diesel spray properties, constant volume combustion chambers can be used to assess the spray characteristics 
of the surrogate and target fuel [101, 143]. Finally, engines that provide optical access to the combustion chamber and allow the application of laser/imaging diagnostics can provide validation data for surrogate fuels in practical combustion devices.

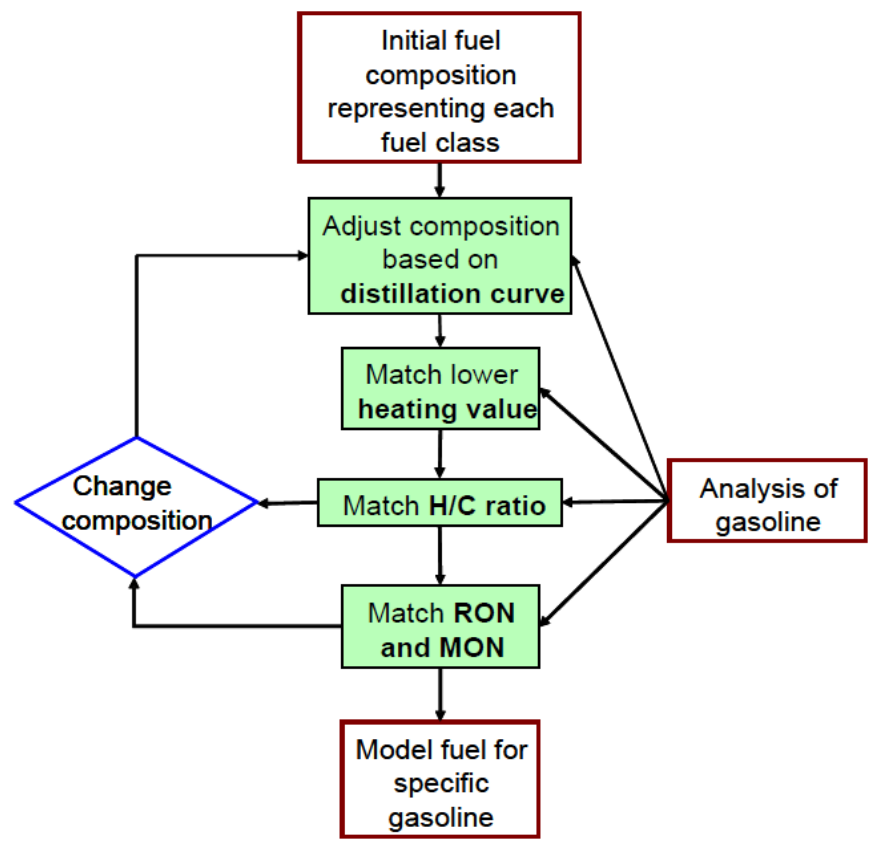

Figure 10. Flow chart for developing model fuels for gasoline [4]. Reprinted with permission from SAE paper 2009-01-0669 (C) 2009 SAE International.

\section{PHYSICAL PROPERTIES}

Physical properties for surrogate components, their mixtures, and target real fuels are needed to simulate combustion of diesel fuel in internal combustion engines. Also when experiments are performed, the physical properties of the diesel surrogate fuel need to match those of the target fuel so that their injection, vaporization, and mixing characteristics are similar. In a recent paper on a computational fluid dynamic model for diesel combustion [144], the physical properties needed to simulate the diesel spray were density, vapor pressure, surface tension, liquid viscosity and thermal conductivity, heat of vaporization, liquid heat capacity, fuel vapor diffusivity, thermal conductivity and viscosity. This work also showed that it is important to properly treat the vaporization properties of a surrogate diesel fuel. In their simulations using a six-component surrogate for diesel fuel, Ra and Reitz demonstrate that light components are more prevalent in the upstream gases of a diesel spray, while heavy components are more prevalent downstream (Fig. 11). Other physical properties that are needed are transport properties of the species in the gas phase (viscosity, thermal conductivity, species transport). As discussed below, Holley et al. [145] show that the most important species for which accurate gas-phase species transport are needed are the fuel components and the light species $\left(\mathrm{OH}, \mathrm{H}, \mathrm{O}, \mathrm{O}_{2}, \mathrm{CO}_{2}\right.$ and $\left.\mathrm{H}_{2} \mathrm{O}\right)$, particularly $\mathrm{O}_{2}$. Recent progress in improving the knowledge of physical properties of surrogate components, their mixtures and real fuels is discussed below. 


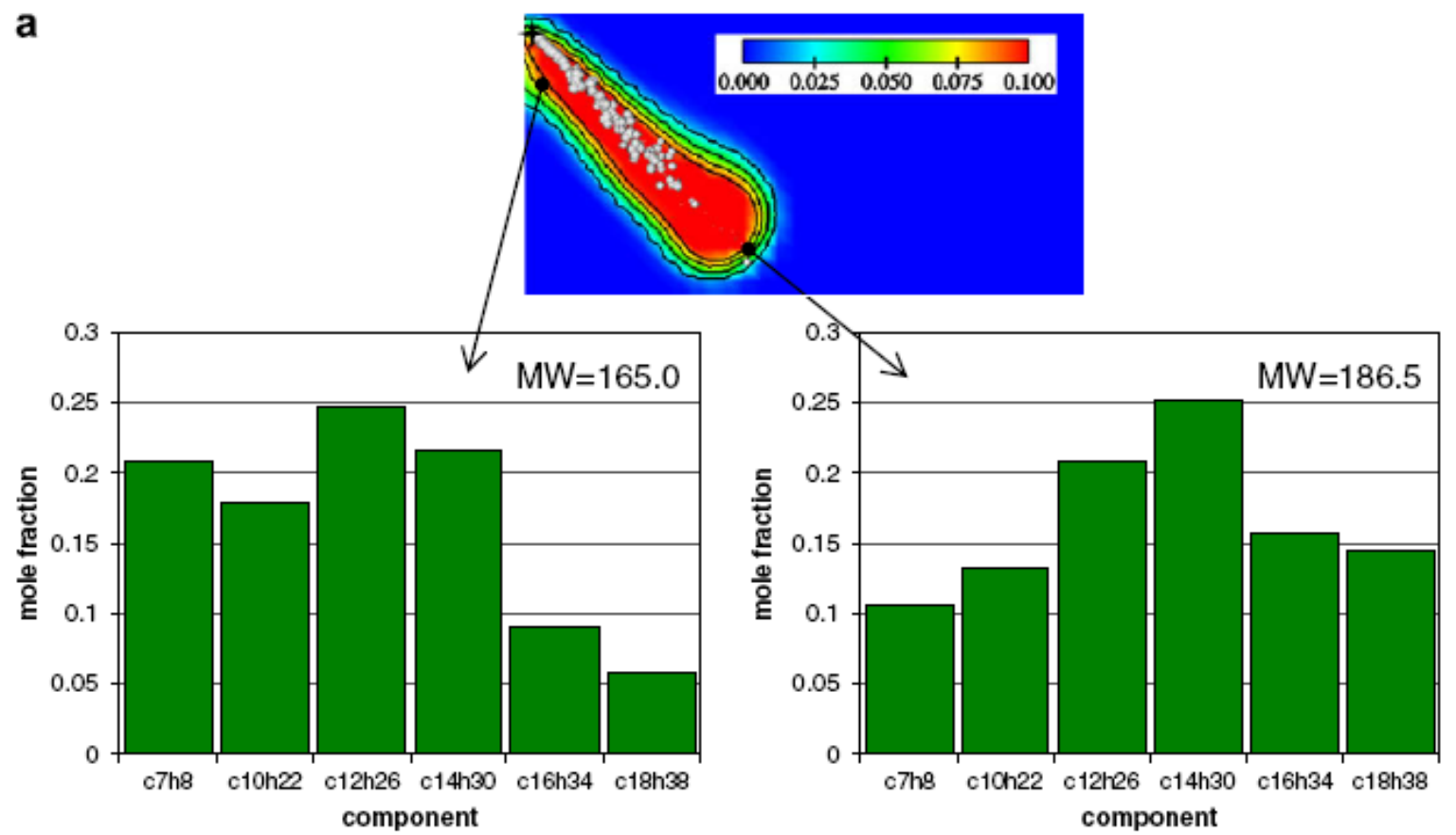

Figure 11. Computed concentration of vaporized hydrocarbons in a surrogate diesel spray from a multi-component vaporization model at $0.5 \mathrm{~ms}$ after start of injection. Reprinted from [144] with permission from Elsevier.

Holley et al. [145] proposed transport properties for n-alkanes up to tetradecane and 1-alkenes up to dodecene based on correlations of corresponding states [146]. They used these new transport properties to model the propagation and extinction of n-dodecane flames. They were able to quantify the relative importance of chemical kinetics and transport properties on flame propagation and extinction. In this paper and a subsequent paper [147], they identified the critical species for which accurate species transport is needed to accurately calculate flame speeds and extinction. Calculations of laminar flame speed showed a high sensitivity to the diffusion coefficient for $\mathrm{O}_{2}$ and some sensitivity for $\mathrm{H}, \mathrm{O}$ and $\mathrm{OH}$. Calculations of flame extinction showed a high sensitivity to the diffusion coefficients of the fuel, $\mathrm{OH}, \mathrm{H}, \mathrm{O}, \mathrm{O}_{2}, \mathrm{CO}_{2}$ and $\mathrm{H}_{2} \mathrm{O}$.

For liquid fuel properties, Caudwell et al. [148] measured the viscosity and density of five hydrocarbons (octane, decane, 1,3-dimethylbenzene, 1,2,3,4-tetrahydronaphthalene, and 1methylnaphthalene) over a temperature range of 298 to $473 \mathrm{~K}$ and a pressure range of 0.1 to 200 $\mathrm{MPa}$. The measurements had relative uncertainties of $2 \%$ for viscosity and $0.2 \%$ for density. Correlations for density and viscosity were developed and compared to literature data.

Hernández-Galván et al. [149] experimentally measured the liquid viscosity of cyclohexane and mixtures of cyclohexane with tetradecane and benzene over a temperature range of 331 to $393 \mathrm{~K}$ and a pressure range of 0.7 to $60 \mathrm{MPa}$. They developed viscosity models that were able to satisfactorily represent the viscosity of the binary systems over the entire pressure, temperature and composition range studied. 
Perkins et al. [150] measured the thermal conductivity of methylcyclohexane and propylcyclohexane over a wide range of temperature (300-600K) and pressure (0.1 to $60 \mathrm{MPa})$. They used the experimental data to develop correlations for thermal conductivity that are estimated to have a relative uncertainty of $4 \%$ at a $95 \%$ confidence level.

Bruno et al. [151, 152] have developed an approach called the advanced distillation curve (ADC) for measuring distillation curves for practical fuels that measures the true thermodynamic state of the fluid. The technique obtains accurate temperatures, pressures and volumes so that the results can be used for equation of state development for the fuel. Equations of state provide functional relationships of density, pressure, temperature and provide other thermodynamic quantities such as heat capacity. They also use gas chromatography and mass spectrometry to characterize the various distillation fractions of the fuel. Such characterizations are needed to specify the vapor composition in the vicinity of fuel droplets in diesel combustion simulations and to validate multi-component vaporization models.

Huber et al. [153] developed a surrogate mixture model to represent the physical properties of a coal-derived liquid fuel. They used gas chromatography with mass spectrometry to analyze the composition of the coal-derived fuel. The coal-derived liquid was mainly composed of cyclic alkanes, especially decalins. An ADC method was used to obtain the distillation properties of the coal-derived fuel. From the experimental data obtained, they developed a five-component surrogate model (n-propylcyclohexane, trans-decalin, alpha-methyldecalin, bicyclohexane, and n-hexadecane) that was able to predict density, speed of sound and viscosity of the target coalderived fuel within 1, 4, and 5\%, respectively, of available experimental data. A low and high molecular weight compound was included in the surrogate to properly predict the initial boiling point and the tail of the target distallation curve. Later, they applied the same approach and derived a seven-component surrogate fuel for a Fischer-Tropsch S-8 jet fuel [42]. The seven components were n-nonane, 2,6-dimethyloctane, 3-methyldecane, n-tridecane, n-tetradecane, npentadecane and n-hexadecane. These components were selected from a list of components actually measured in the S-8 jet fuel. The amount of each component was optimizied to obtain the best agreement with the expermentally measured density, viscosity, sound speed and distillation curve of S-8 jet fuel. They found that the overall shape of the distillation curve of the surrogate is determined by only four components. However, small amounts of a low and a high molecular weight n-alkane were added to the surrogate to achieve the desired initial boiling behavior and the proper tail of the end of the distallation curve. The inclusion of branched hydrocarbons was necessary to accurately simulate the thermal conductivity of the target fuel. The approach that Huber et al. have developed also can be applied to matching diesel surrogate fuels to real diesel fuels. 


\section{RECOMMENDATIONS}

A general theme from the above review is that data are required for compounds with higher molecular weights as well as molecular structures that are more representative of compounds found in market diesel fuels. Having accurate compositional data for market diesel fuels is therefore an important step in creating representative diesel surrogate fuels, and work to quantify typical compositions and variabilities among market diesel fuels would be of value. Also, it would be helpful to better understand the compositional characteristics of current and expected future blending streams (e.g., those obtained through Fischer-Tropsch processes; upgrading of oil sands, oil shale, and coal deposits; pyrolysis; hydrotreatment of bio-derived oils; biological processing of biomass; etc.).

Relevant target-fuel compositional information can be used to guide the selection of individual pure compounds for use in formulating the surrogate. A set of pure compounds used to formulate a surrogate is termed a surrogate palette. Successful diesel surrogate palettes are likely to include n-, iso-, and cyclo-alkanes, as well as aromatics and tetralins, all in the C12 to C22 range. The iso-alkanes are likely to have one (or perhaps two) methyl branches near one end of the chain. The cyclo-alkanes and aromatics are likely to have one ring with multiple shorter-chain substitutions. Unfortunately, aside from the n-alkanes, representative diesel-fuel components are typically difficult and expensive ( $\sim 5000 / \mathrm{kg}$ ) to procure at high purity $(\geq 98 \%)$, and as a result, the literature contains only limited (if any) thermophysical and chemical characterization data for them. Hence, it is recommended that sources for these high-purity pure compounds be developed (e.g., by custom synthesis or through separation and purification from actual refinery streams). A centrally administered effort could take advantage of economies of scale and accelerate progress by providing these compounds to the research community at a lower cost. In addition, if sufficient quantities of the pure compounds could be obtained, a time-invariant diesel surrogate fuel could be developed and provided to the community as a high-precision standard reference material.

The generally limited availability and higher cost of representative diesel-range pure compounds makes it advisable to select the surrogate palette carefully. If the chemical complexity of the surrogate is greater than necessary, then fuel costs and computational costs to use the surrogate will be unnecessarily high. To avoid this outcome, engine and/or combustion-vessel data acquired using well-characterized target fuels should be compared to data obtained at the same conditions using corresponding surrogate fuels. These results should show how accurately compositional, volatility, ignition-quality, and/or other characteristics must be matched in order for the surrogate to reproduce the desired behaviors of the target fuel. Of course the degree of chemical fidelity required is likely to depend on what combustion parameters need to be matched, the accuracy required for this matching, and what combustion strategy is being used. Once they have been identified, methodologies for formulating successful diesel surrogates 
should be reported in detail. Easy-to-use software tools also would be of great value for assisting in the formulation of optimal diesel surrogates, given desired matching criteria between the target and surrogate fuels.

Fundamental physical and transport property data will be needed for each of the pure compounds comprising the diesel surrogate palette. Chemical characterization data should be acquired in fundamental experiments such as shock tubes, jet-stirred and variable-pressure flow reactors, and rapid compression machines to determine not just ignition-delay times, but also species histories. Species histories are essential for the rigorous validation of each chemical-kinetic mechanism for each pure compound in the palette, and these mechanisms should be developed in parallel. In addition, it would be of interest to compare pure-compound ignition delays measured using an IQT to those measured using more fundamental experiments, and elucidate the reasons for any observed discrepancies.

Data for the individual pure compounds in a palette must be combined to develop accurate models for the behaviors of their mixtures. Specifically, validated mixture models should be developed for chemical kinetics (including ignition delay), volatility, and transport properties. These models, especially those for chemical-kinetic processes, should be reduced to be as simple as possible while still achieving the required accuracy. This is essential if the surrogate is to be employed in practical CFD-based optimizations of engine designs, which is ostensibly the ultimate goal of surrogate-development efforts. The kinetic mechanism reduction process should be automated, and it should include error estimation. Faster chemistry solvers would be of significant value for enabling computationally tractable surrogate models.

Finally, carefully controlled measurements should be made with the surrogate fuel in engine or combustion-vessel experiments, and the results should be compared with CFD results at the same conditions. These comparisons should be made for various combustion strategies and over a wide range of operating conditions within each strategy. This will help assist in determining the extent to which combustion models using the surrogate actually reproduce the physical and chemical processes of interest in practical combustion devices. The surrogate palette, formulation methodology, kinetic models, property data, etc. can then be refined and/or supplemented until predictive modeling capability is achieved.

\section{SUMMARY}

Recent advances in the development of surrogate fuels for diesel have been reviewed. For the chemical class of large n-alkanes, there has been considerable progress made on chemical kinetic modeling and experimental investigations. Significant progress also has been made in all the fuel classes of iso-alkanes, cycloalkanes and aromatics. However, limited work on the fuel class of tetrahydronaphthalenes (tetralins) could be found in the literature. For reducing the large 
chemical kinetic models that result from surrogate fuel model development, significant progress has been made on new mechanism reduction methods.

Recommendations for future work have been made. With regard to pure components, fundamental experimental data is needed to fill out the higher carbon range of diesel fuel (C15 to C20). This is difficult to do experimentally because of the high boiling point of these hydrocarbons and computationally because of the large number of species and reactions that are needed. There is a considerable gap in the work on the iso-alkane chemical class. The isoalkanes in diesel fuel are lightly branched with one or two methyl side groups. No fuel component models or experimental measurements of such hydrocarbons in the carbon range of diesel fuel have been made to the author's knowledge. For cycloalkanes, most of the work has been done on the light end of the carbon range of diesel fuel. For work on multi-component surrogate fuels, there is again a lack of work on surrogate fuels that have components to represent the high molecular weight end of diesel fuel.

\section{ACKNOWLEDGEMENTS}

The authors thank the members of the Coordinating Research Council AVFL-18 panel for their helpful comments on this review paper. This work was supported by the U.S. Department of Energy, Office of Vehicle Technologies, and the authors thank program managers Gurpreet Singh and Kevin Stork for their support of this effort. The work of W.J. Pitz was performed under the auspices of the U.S. Department of Energy by Lawrence Livermore National Laboratory under Contract DE-AC52-07NA27344. The work of C.J. Mueller was conducted at the Combustion Research Facility, Sandia National Laboratories, Livermore, California. Sandia is a multi-program laboratory operated by Sandia Corporation, a Lockheed Martin Company, for the U.S. Department of Energy's National Nuclear Security Administration under contract DEAC04-94AL85000.

\section{REFERENCES}

1. J. T. Farrell, N. P. Cernansky, F. L. Dryer, D. G. Friend, C. A. Hergart, C. K. Law, R. McDavid, C. J. Mueller and H. Pitsch, "Development of an experimental database and kinetic models for surrogate diesel fuels," SAE Paper 2007-01-0201, 2007 SAE World Congress, Detroit, MI, 2007.

2. W. J. Pitz, N. P. Cernansky, F. L. Dryer, F. Egolfopoulos, J. T. Farrell, D. G. Friend and H. Pitsch, "Development of an Experimental Database and Kinetic Models for Surrogate Gasoline Fuels," SAE 2007 Transactions Journal of Passenger Cars - Mechanical Systems, SAE Paper 2007-01-0175, 2007.

3. M. Colket, J. T. Edwards, S. Williams, N. P. Cernansky, D. L. Miller, F. N. Egolfopoulos, P. Lindstedt, K. Seshadri, F. L. Dryer, C. K. Law, D. G. Friend, D. B. Lenhert, H. Pitsch, A. Sarofim, M. Smooke and W. Tsang, "Development of an experimental database and kinetic models for surrogate jet fuels," 45th AIAA Aerospace Sciences Meeting and Exhibit, Reno, Nevada, paper no. AIAA-2007-0770, 2007. 
4. K. V. Puduppakkam, L. Liang, C. V. Naik, E. Meeks and B. G. Bunting, "Combustion and Emissions Modeling of a Gasoline HCCI Engine Using Model Fuels," Society of Automotive Engineers Paper No. 2009-01-0669, 2009.

5. H. Xu, Z. Yang, M. Chaos and F. L. Dryer, "Surrogate Jet Fuel Mixture Formulation and Development of Experimental Databases," JANNAF 42nd Combustion Subcommittee, Boston, MA, 2008.

6. J. M. Simmie, "Detailed chemical kinetic models for the combustion of hydrocarbon fuels," Progress in Energy and Combustion Science 29 (6) (2003) 599-634.

7. F. Battin-Leclerc, "Detailed chemical kinetic models for the low-temperature combustion of hydrocarbons with application to gasoline and diesel fuel surrogates," Progress in Energy and Combustion Science 34 (4) (2008) 440-498.

8. C. K. Westbrook, W. J. Pitz, O. Herbinet, H. J. Curran and E. J. Silke, "A Detailed Chemical Kinetic Reaction Mechanism for n-Alkane Hydrocarbons from n-Octane to n-Hexadecane," Combust. Flame 156 (1) (2009) 181-199.

9. J. Biet, M. H. Hakka, V. Warth, P. A. Glaude and F. Battin-Leclerc, "Experimental and modeling study of the low-temperature oxidation of large alkanes," Energy \& Fuels 22 (4) (2008) 2258-2269.

10. H. J. Curran, P. Gaffuri, W. J. Pitz and C. K. Westbrook, "A Comprehensive Modeling Study of n-Heptane Oxidation," Combust. Flame 114 (1-2) (1998) 149-177.

11. G. M. Come, V. Warth, P. A. Glaude, R. Fournet, F. Battin-Leclerc and G. Scacchi, "Computer-Aided Design of Gas-Phase Oxidation Mechanisms-Application to the Modelling of n-Heptane and Iso-Octane Oxidation," Proc. Combust. Inst. 26 (1996) 755-762.

12. H.-P. S. Shen, J. Steinberg, J. Vanderover and M. A. Oehlschlaeger, "A Shock Tube Study of the Ignition of n-Heptane, n-Decane, n-Dodecane, and n-Tetradecane at Elevated Pressures," Energy \& Fuels 23 (5) (2009) 2482-2489.

13. X. You, F. N. Egolfopoulos and H. Wang, "Detailed and simplified kinetic models of ndodecane oxidation: The role of fuel cracking in aliphatic hydrocarbon combustion," Proc.

Combust. Inst. 32 (1) (2009) 403-410.

14. B. Sirjean, E. Dames, D. A. Sheen, X.-Q. You, C. Sung, A. T. Holley, F. N. Egolfopoulos, H. Wang, S. S. Vasu, D. F. Davidson, R. K. Hanson, H. Pitsch, C. T. Bowman, A. Kelle, C. K. Law, W. Tsang, N. P. Cernansky, D. L. Miller, A. Violi and R. P. Lindstedt, "A hightemperature chemical kinetic model of n-alkane oxidation, JetSurF version 0.2," http://melchior.usc.edu/JetSurF/Version0_2/Index.html, 2009.

15. H. R. Zhang, E. G. Eddings, A. F. Sarofim and C. K. Westbrook, "Fuel dependence of benzene pathways," Proc. Combust. Inst. 32 (1) (2009) 377-385.

16. H. R. Zhang, E. G. Eddings and A. F. Sarofim, "A Journey from n-Heptane to Liquid Transportation Fuels. 1. The Role of the Allylic Radical and Its Related Species in Aromatic Precursor Chemistry," Energy \& Fuels 22 (2) (2008) 945-953.

17. H. R. Zhang, E. G. Eddings and A. F. Sarofim, "Criteria for selection of components for surrogates of natural gas and transportation fuels," Proc. Combust. Inst. 31 (1) (2007) 401-409. 18. H. R. Zhang, E. G. Eddings and A. F. Sarofim, "Combustion reactions of paraffin components in liquid transportation fuels using generic rates," Combust. Sci. Technol. 179 (1-2) (2007) 61-89.

19. M. H. Hakka, P.-A. Glaude, O. Herbinet and F. Battin-Leclerc, "Experimental study of the oxidation of large surrogates for diesel and biodiesel fuels," Combust. Flame 156 (11) (2009) 2129-2144. 
20. S. S. Vasu, D. F. Davidson, Z. Hong, V. Vasudevan and R. K. Hanson, "n-Dodecane oxidation at high-pressures: Measurements of ignition delay times and $\mathrm{OH}$ concentration timehistories," Proc. Combust. Inst. 32 (1) (2009) 173-180.

21. J. E. Dec, "A Conceptual Model of DI Diesel Combustion Based on Laser-Sheet Imaging," Soc. Auto. Engin. Trans. 106 (3) (1997) 1319-1348.

22. C. L. Genzale, R. D. Reitz and M. P. B. Musculus, "Effects of Piston Bowl Geometry on Mixture Development and Late-Injection Low-Temperature Combustion in a Heavy-Duty Diesel Engine," Society of Automotive Engineers Paper No. 2008-01-1330, 2008.

23. M. P. B. Musculus, T. Lachaux, L. M. Pickett and C. A. Idicheria, "End-of-Injection OverMixing and Unburned Hydrocarbon Emissions in Low-Temperature-Combustion Diesel Engines," Society of Automotive Engineers paper No. 2007-01-0907, 2007.

24. D. F. Davidson, D. R. Haylett and R. K. Hanson, "Development of an aerosol shock tube for kinetic studies of low-vapor-pressure fuels," Combust. Flame 155 (1-2) (2008) 108-117. 25. V. P. Zhukov, V. A. Sechenov and A. Y. Starikovskii, "Autoignition of n-decane at high pressure," Combust. Flame 153 (1-2) (2008) 130-136.

26. K. Kumar, G. Mittal and C.-J. Sung, "Autoignition of n-decane under elevated pressure and low-to-intermediate temperature conditions," Combust. Flame In Press, Corrected Proof (2009) 27. U. Pfahl, K. Fieweger and G. Adomeit, "Self-Ignition of Diesel-Relevant Hydrocarbon-Air Mixtures under Engine Conditions," Proc. Combust. Inst. 26 (1996) 781-789.

28. G. Bikas and N. Peters, "Kinetic modelling of n-decane combustion and autoignition," Combust. Flame 126 (1-2) (2001) 1456-1475.

29. K. Kumar and C.-J. Sung, "Laminar flame speeds and extinction limits of preheated ndecane/O2/N2 and n-dodecane/O2/N2 mixtures," Combust. Flame 151 (1-2) (2007) 209-224. 30. P. Dagaut, M. Reuillon and M. Cathonnet, "High-Pressure Oxidation of Liquid Fuels from Low to High-Temperature .3. N-Decane," Combust. Sci. Technol. 103 (1-6) (1994) 349-359.

31. D. B. Lenhert, N. P. Cernansky and D. L. Miller, "The Oxidation of Large Molecular Weight Hydrocarbons in a Pressurized Flow Reactor," 4th Joint Meeting of the U.S. Sections of the Combustion Institute, Philadelphia, PA, 2005.

32. M. Sjöberg, J. E. Dec and W. Hwang, "Thermodynamic and Chemical Effects of EGR and Its Constituents on HCCI Autoignition," Society of Automotive Engineers SAE 2007-01-0207 (2007).

33. E. F. Obert, Internal combustion engines and air pollution, Third edition, Harper and Row, New York (1973).

34. ASTM-International, "ASTM Standard D 613, Standard Test Method for Cetane Number of Diesel Fuel Oil," West Conshohocken, PA, www.astm.org, (2008).

35. M. J. Murphy, J. D. Taylor and R. L. McCormick, "Compendium of Experimental Cetane Number Data," National Renewable Energy Laboratory, NREL/SR-540-36805, www.nrel.gov/vehiclesandfuels/pdfs/sr368051.pdf (2004).

36. M. A. Oehlschlaeger, J. Steinberg, C. K. Westbrook and W. J. Pitz, "The autoignition of isocetane at high to moderate temperatures and elevated pressures: Shock tube experiments and kinetic modeling," Combust. Flame 156 (11) (2009) 2165-2172.

37. H. J. Curran, P. Gaffuri, W. J. Pitz and C. K. Westbrook, "A Comprehensive Modeling Study of iso-Octane Oxidation," Combust. Flame 129 (2002) 253-280.

38. P. Dagaut and K. Hadj-Ali, "Chemical Kinetic Study of the Oxidation of Isocetane (2,2,4,4,6,8,8-Heptamethylnonane) in a Jet-stirred Reactor: Experimental and Modeling," Energy \& Fuels 23 (5) (2009) 2389-2395. 
39. A. Agosta, N. P. Cernansky, D. L. Miller, T. Faravelli and E. Ranzi, "Reference components of jet fuels: kinetic modeling and experimental results," Experimental Thermal and Fluid Science 28 (7) (2004) 701-708.

40. F. Battin-Leclerc, F. Bounaceur, G. M. Come, R. Fournet, P. A. Glaude, G. Scacchi and V. Warth, "EXGAS-ALKANES:A Software for the Automatic Generation of Mechanisms for the Oxidation of Alkanes," CNRS, 2004.

41. E. Ranzi, A. Frassoldati, T. Faravelli and A. Cuoci, "Lumped Kinetic Modeling of the Oxidation of Isocetane (2,2,4,4,6,8,8-Heptamethylnonane) in a Jet-Stirred Reactor (JSR)," Energy \& Fuels 23 (10) (2009) 5287-5289.

42. M. L. Huber, B. L. Smith, L. S. Ott and T. J. Bruno, "Surrogate Mixture Model for the Thermophysical Properties of Synthetic Aviation Fuel S-8: Explicit Application of the Advanced Distillation Curve," Energy \& Fuels 22 (2) (2008) 1104-1114.

43. W. S. Neill, W. L. Chippior, J. Cooley, M. Doma, C. Fairbridge, R. Falkiner, R. L.

McCormick and K. Mitchell, "Emissions from Heavy-Duty Diesel Engine with EGR using Fuels Derived from Oil Sands and Conventional Crude," Society of Automotive Engineers Paper No. 2003-01-3144, 2003.

44. E. J. Silke, W. J. Pitz, C. K. Westbrook and M. Ribaucour, "Detailed Chemical Kinetic Modeling of Cyclohexane Oxidation," J. Phys. Chem. A 111 (19) (2007) 3761-3775.

45. F. Buda, B. Heyberger, R. Fournet, P. A. Glaude, V. Warth and F. Battin-Leclerc, "Modeling of the gas-phase oxidation of cyclohexane," Energy \& Fuels 20 (4) (2006) 14501459.

46. C. Cavallotti, R. Rota, T. Faravelli and E. Ranzi, "'Ab initio" evaluation of primary cyclohexane oxidation reaction rates," Proc. Combust. Inst. 31 (2007) 201-209.

47. O. Lemaire, M. Ribaucour, M. Carlier and R. Minetti, "The Production of Benzene in the Low-Temperature Oxidation of Cyclohexane, Cyclohexene, and Cyclohexa-1,3-diene," Combust. Flame 127 (2001) 1971-1980.

48. A. E. Bakali, M. Braun-Unkhoff, P. Dagaut, P. Frank and M. Cathonnet, "Detailed Kinetic Reaction Mechanism for Cyclohexane Oxidation at Pressure up to Ten Atmospheres," Proc. Combust. Inst. 28 (2000) 1631-1638.

49. H. R. Zhang, L. K. Huynh, N. Kungwan, Z. Yang and S. Zhang, "Combustion Modeling and Kinetic Rate Calculations for a Stoichiometric Cyclohexane Flame. 1. Major Reaction Pathways," J. Phys. Chem. A 111 (19) (2007) 4102-4115.

50. M. E. Law, P. R. Westmoreland, T. A. Cool, J. Wang, N. Hansen, C. A. Taatjes and T. Kasper, "Benzene precursors and formation routes in a stoichiometric cyclohexane flame," Proc. Combust. Inst. 31 (1) (2007) 565-573.

51. R. X. Fernandes, J. Zador, L. E. Jusinski, J. A. Miller and C. A. Taatjes, "Formally direct pathways and low-temperature chain branching in hydrocarbon autoignition: the cyclohexyl + O2 reaction at high pressure," Physical Chemistry Chemical Physics 11 (9) (2009) 1320-1327. 52. G. Mittal and C.-J. Sung, "Autoignition of methylcyclohexane at elevated pressures," Combust. Flame 156 (9) (2009) 1852-1855.

53. W. J. Pitz, C. V. Naik, T. N. Mhaolduin, C. K. Westbrook, H. J. Curran, J. P. Orme and J. M. Simmie, "Modeling and experimental investigation of methylcyclohexane ignition in a rapid compression machine," Proc. Combust. Inst. 31 (1) (2007) 267-275.

54. Y. Yang and A. L. Boehman, "Experimental study of cyclohexane and methylcyclohexane oxidation at low to intermediate temperature in a motored engine," Proc. Combust. Inst. 32 (1) (2009) 419-426. 
55. S. S. Vasu, D. F. Davidson, Z. Hong and R. K. Hanson, "Shock Tube Study of Methylcyclohexane Ignition over a Wide Range of Pressure and Temperature," Energy \& Fuels 23 (1) (2009) 175-185.

56. S. S. Vasu, D. F. Davidson and R. K. Hanson, "OH time-histories during oxidation of nheptane and methylcyclohexane at high pressures and temperatures," Combust. Flame 156 (4) (2009) 736-749.

57. S. M. Daley, A. M. Berkowitz and M. A. Oehlschlaeger, "A shock tube study of cyclopentane and cyclohexane ignition at elevated pressures," Int. J. Chem. Kinet. 40 (10) (2008) 624-634.

58. J. Vanderover and M. A. Oehlschlaeger, "Ignition Time Measurements for Methylcylcohexane- and Ethylcyclohexane-Air Mixtures at Elevated Pressures," Int. J. Chem. Kinet. 41 (2) (2009) 82-91.

59. R. Sivaramakrishnan and J. V. Michael, "Shock tube measurements of high temperature rate constants for $\mathrm{OH}$ with cycloalkanes and methylcycloalkanes," Combust. Flame 156 (5) (2009) 1126-1134.

60. A. Ciajolo, A. Tregrossi, M. Mallardo, T. Faravelli and E. Ranzi, "Experimental and kinetic modeling study of sooting atmospheric-pressure cyclohexane flame," Proc. Combust. Inst. 32 (1) (2009) 585-591.

61. T. Bieleveld, A. Frassoldati, A. Cuoci, T. Faravelli, E. Ranzi, U. Niemann and K. Seshadri, "Experimental and kinetic modeling study of combustion of gasoline, its surrogates and components in laminar non-premixed flows," Proc. Combust. Inst. 32 (1) (2009) 493-500.

62. M. A. Oehlschlaeger, H.-P. S. Shen, A. Frassoldati, S. Pierucci and E. Ranzi, "Experimental and Kinetic Modeling Study of the Pyrolysis and Oxidation of Decalin," Energy \& Fuels 23 (3) (2009) 1464-1472.

63. Y. Yang and A. L. Boehman, "Oxidation chemistry of cyclic hydrocarbons in a motored engine: methylcyclopentane, tetralin, and decalin," Combust. Flame (2009) In press.

64. K. Chae and A. Violi, "Thermal decomposition of decalin: An Ab initio study," Journal of Organic Chemistry 72 (9) (2007) 3179-3185.

65. A. Ristori, P. Dagaut, A. E. Bakali and M. Cathonnet, "The oxidation of Npropylcyclohexane: Experimental results and kinetic modeling," Combust. Sci. Technol. 165 (2001) 197-228.

66. Y. Sakai, A. Miyoshi, M. Koshi and W. J. Pitz, "A kinetic modeling study on the oxidation of primary reference fuel-toluene mixtures including cross reactions between aromatics and aliphatics," Proc. Combust. Inst. 32 (2009) 411-418.

67. M. A. Oehlschlaeger, D. F. Davidson and R. K. Hanson, "Thermal decomposition of toluene: Overall rate and branching ratio," Proc. Combust. Inst. 31 (1) (2007) 211-219. 68. Y. Sakai, T. Inamura, T. Ogura, M. Koshi and W. J. Pitz, "Detailed Kinetic Modeling of Toluene Combustion over a Wide Range of Temperature and Pressure," 2007 JSAE/SAE International Fuels and Lubricants Meeting, SAE 2007-01-1885, Kyoto TERRSA, Japan, 2007. 69. M. Mehl, H. J. Curran, W. J. Pitz and C. K. Westbrook, "Detailed Kinetic Modeling of Gasoline Surrogate Mixtures," U.S. National Combustion Meeting, Ann Arbor, MI, 2009. 70. M. Mehl, H. J. Curran, W. J. Pitz and C. K. Westbrook, "Chemical kinetic modeling of component mixtures relevant to gasoline," European Combustion Meeting, Vienna, Austria, 2009.

71. G. Mittal and C.-J. Sung, "Autoignition of toluene and benzene at elevated pressures in a rapid compression machine," Combust. Flame 150 (4) (2007) 355-368. 
72. H.-P. S. Shen, J. Vanderover and M. A. Oehlschlaeger, "A shock tube study of the autoignition of toluene/air mixtures at high pressures," Proc. Combust. Inst. 32 (1) (2009) 165-172. 73. D. F. Davidson, B. M. Gauthier and R. K. Hanson, "Shock tube ignition measurements of iso-octane/air and toluene/air at high pressures," Proc. Combust. Inst. 30 (1) (2005) 1175-1182. 74. G. Blanquart, P. Pepiot-Desjardins and H. Pitsch, "Chemical mechanism for high temperature combustion of engine relevant fuels with emphasis on soot precursors," Combust. Flame 156 (3) (2009) 588-607.

75. H.-P. S. Shen and M. A. Oehlschlaeger, "The autoignition of C8H10 aromatics at moderate temperatures and elevated pressures," Combust. Flame 156 (5) (2009) 1053-1062.

76. A. Roubaud, O. Lemaire, R. Minetti and L. R. Sochet, "High pressure auto-ignition and oxidation mechanisms of o-xylene, o-ethyltoluene, and n-butylbenzene between 600 and $900 \mathrm{~K}$," Combust. Flame 123 (4) (2000) 561-571.

77. A. Roubaud, R. Minetti and L. R. Sochet, "Oxidation and combustion of low alkylbenzenes at high pressure: comparative reactivity and auto-ignition," Combust. Flame 121 (3) (2000) 535541.

78. T. A. Litzinger, K. Brezinsky and I. Glassman, "Gas-phase oxidation of isopropylbenzene at high temperature," The Journal of Physical Chemistry 90 (3) (2002) 508-513.

79. G. Bikas, "Kinetic Mechanisms for Hydrocarbon Ignition," RWTH Aachen University, Aachen, 2001.

80. S. Honnet, K. Seshadri, U. Niemann and N. Peters, "A surrogate fuel for kerosene," Proc. Combust. Inst. 32 (1) (2009) 485-492.

81. E. Riesmeier, S. Honnet and N. Peters, "Flamelet modeling of pollutant formation in a gas turbine combustion chamber using detailed chemistry for a kerosene model fuel," Journal of Engineering for Gas Turbines and Power-Transactions of the Asme 126 (4) (2004) 899-905. 82. E. Pousse, P. A. Glaude, R. Fournet and F. Battin-Leclerc, "A lean methane premixed laminar flame doped with components of diesel fuel: I. n-Butylbenzene," Combust. Flame 156 (5) (2009) 954-974.

83. K. Mati, A. Ristori, G. Pengloan and P. Dagaut, "Oxidation of 1-methylnaphthalene at 1-13 atm: Experimental study in a JSR and detailed chemical kinetic modeling," Combust. Sci. Technol. 179 (7) (2007) 1261-1285.

84. R. Bounaceur, P. A. Glaude, R. Fournet, F. Battin-Leclerc, S. Jay and A. P. da Cruz, "Kinetic modelling of a surrogate diesel fuel applied to 3D auto-ignition in HCCI engines," International Journal of Vehicle Design 44 (1-2) (2007) 124-142.

85. H. Pitsch, "Detailed kinetic reaction mechanism for ignition and oxidation of [alpha]methylnaphthalene," Symposium (International) on Combustion 26 (1) (1996) 721-728. 86. C. R. Shaddix, K. Brezinsky and I. Glassman, "Oxidation of 1-methylnaphthalene," Symposium (International) on Combustion 24 (1) (1992) 683-690.

87. R. D. Wilk, "Preignition oxidation characteristics of hydrocarbon fuels," Department of Mechanical Engineering and Mechanics, Drexel University, Philidelphia, PA, 1986.

88. R. Lemaire, A. Faccinetto, E. Therssen, M. Ziskind, C. Focsa and P. Desgroux, "Experimental comparison of soot formation in turbulent flames of Diesel and surrogate Diesel fuels," Proc. Combust. Inst. 32 (1) (2009) 737-744.

89. W. Hentschel, K.-P. Schindler and O. Haahtela, "European Diesel Research IDEA -Experimental Results from DI Diesel Engine Investigations," SAE Transactions, SAE Paper 941954, 1994. 
90. M. Colket, T. Edwards, S. Williams, N. P. Cernansky, D. L. Miller, F. N. Egolfopoulos, F. L. Dryer, J. Bellan, P. Lindstedt, K. Seshadri, H. Pitsch, A. Sarofim, M. Smooke and W. Tsang, "Identification of Target Validation Data for Development of Surrogate Jet Fuels," 46th AIAA Aerospace Sciences Meeting and Exhibit, Reno, Nevada, paper no. AIAA-2008-0972, 2008. 91. D. B. Olson, J. C. Pickens and R. J. Gill, "The effects of molecular structure on soot formation II. Diffusion flames," Combust. Flame 62 (1) (1985) 43-60.

92. Y. Yang, A. L. Boehman and R. J. Santoro, "A study of jet fuel sooting tendency using the threshold sooting index (TSI) model," Combust. Flame 149 (1-2) (2007) 191-205.

93. S. Kook and L. M. Pickett, "Combustion and Soot Processes of Conventional and Surrogate Jet Fuels at High-Temperature and High-Pressure Conditions," U.S. National Combustion Meeting, Ann Arbor, 2009.

94. R. H. Natelson, M. S. Kurman, N. P. Cernansky and D. L. Miller, "Experimental investigation of surrogates for jet and diesel fuels," Fuel 87 (10-11) (2008) 2339-2342. 95. F. Douce, N. Djebaïli-Chaumeix, C. E. Paillard, C. Clinard and J. N. Rouzaud, "Soot formation from heavy hydrocarbons behind reflected shock waves," Proc. Combust. Inst. 28 (2) (2000) 2523-2529.

96. O. Mathieu, N. Djebaïli-Chaumeix, C.-E. Paillard and F. Douce, "Experimental study of soot formation from a diesel fuel surrogate in a shock tube," Combust. Flame 156 (8) (2009) 15761586.

97. K. Nakakita, K. Akihama, W. Weissman and J. T. Farrell, "Effect of the hydrocarbon molecular structure in diesel fuel on the in-cylinder soot formation and exhaust emissions," International Journal of Engine Research 6 (3) (2005) 187-205.

98. U. Steil, M. Braun-Unkhoff and M. Aigner, "An experimental and modeling study on the auto ignition of kerosene and surrogate fuel mixture," American Institute of Aeronautics and Astronautics paper no. AIAA 2008-973, 2009.

99. K. Mati, A. Ristori, S. Gail, G. Pengloan and P. Dagaut, "The oxidation of a diesel fuel at 110 atm: Experimental study in a JSR and detailed chemical kinetic modeling," Proc. Combust. Inst. 31 (2) (2007) 2939-2946.

100. K.-J. Myong, H. Suzuki, J. Senda and H. Fujimoto, "Evaporation characteristics of multicomponent fuel," Fuel 85 (17-18) (2006) 2632-2639.

101. K.-J. Myong, H. Suzuki, J. Senda and H. Fujimoto, "Spray inner structure of evaporating multi-component fuel," Fuel 87 (2) (2008) 202-210.

102. W. Sun, Z. Chen, X. Gou and Y. Ju, "A Path Flux Analysis Method for the Reduction of Chemical Kinetic Mechanism," U.S. National Combustion Meeting, Ann Arbor, MI, 2009.

103. K. E. Niemeyer, M. P. Raju and C. J. Sung, "Skeletal Mechanism Generation for Surrogate Fuels Using Directed Relation Graph with Error Propagation and Sensitivity Analysis," U.S. National Combustion Meeting, Ann Arbor, 2009.

104. E. Ranzi, T. Faravelli, P. Gaffuri and A. Sogaro, "Low-temperature combustion: Automatic generation of primary oxidation reactions and lumping procedures," Combust. Flame 102 (1-2) (1995) 179-192.

105. T. F. Lu and C. K. Law, "On the applicability of directed relation graphs to the reduction of reaction mechanisms," Combust. Flame 146 (3) (2006) 472-483.

106. B. Bhattacharjee, D. A. Schwer, P. I. Barton and W. H. Green, "Optimally-reduced kinetic models: reaction elimination in large-scale kinetic mechanisms," Combust. Flame 135 (3) (2003) 191-208. 
107. K. J. Hughes, M. Fairweather, J. F. Griffiths, R. Porter and A. S. Tomlin, "The application of the QSSA via reaction lumping for the reduction of complex hydrocarbon oxidation mechanisms," Proc. Combust. Inst. 32 (1) (2009) 543-551.

108. S. R. Tonse, M. S. Day and N. J. Brown, "Dynamic reduction of a CH4/air chemical mechanism appropriate for investigating vortex-flame interactions," Int. J. Chem. Kinet. 39 (4) (2007) 204-220.

109. W. H. Green, P. I. Barton, B. Bhattacharjee, D. M. Matheu, D. A. Schwer, J. Song, R. Sumathi, H. H. Carstensen, A. M. Dean and J. M. Grenda, "Computer construction of detailed chemical kinetic models for gas-phase reactors," Industrial \& Engineering Chemistry Research 40 (23) (2001) 5362-5370.

110. L. Liang, J. G. Stevens, S. Raman and J. T. Farrell, "The use of dynamic adaptive chemistry in combustion simulation of gasoline surrogate fuels," Combust. Flame 156 (7) (2009) 1493-1502.

111. D. A. Schwer, J. E. Tolsma, W. H. Green and P. I. Barton, "On upgrading the numerics in combustion chemistry codes," Combust. Flame 128 (3) (2002) 270-291.

112. S. M. Aceves, D. L. Flowers, F. Espinosa-Loza, J. Martinez-Frias, J. E. Dec, M. Sjöberg, R.W. and R. P. Hessel, "Spatial Analysis of Emissions Sources for HCCI Combustion at Low Loads Using a Multi-Zone Model," Society of Automotive Engineers, SAE Paper 2004-01-1910 (2004).

113. T. F. Lu and C. K. Law, "Toward accommodating realistic fuel chemistry in large-scale computations," Progress in Energy and Combustion Science 35 (2) (2009) 192-215.

114. T. Lu, C. K. Law, C. S. Yoo and J. H. Chen, "Dynamic stiffness removal for direct numerical simulations," Combust. Flame 156 (8) (2009) 1542-1551.

115. K. Seshadri, T. Lu, O. Herbinet, S. Humer, U. Niemann, W. J. Pitz, R. Seiser and C. K. Law, "Experimental and kinetic modeling study of extinction and ignition of methyl decanoate in laminar non-premixed flows," Proc. Combust. Inst. 32 (1) (2009) 1067-1074.

116. J. Prager, H. N. Najm, M. Valorani and D. A. Goussis, "Skeletal mechanism generation with CSP and validation for premixed n-heptane flames," Proc. Combust. Inst. 32 (1) (2009) 509-517.

117. S. H. Lam and D. A. Coussis, "Understanding complex chemical kinetics with computational singular perturbation," Symposium (International) on Combustion 22 (1) (1989) 931-941.

118. P. Pepiot-Desjardins and H. Pitsch, "An efficient error-propagation-based reduction method for large chemical kinetic mechanisms," Combust. Flame 154 (1-2) (2008) 67-81.

119. T. Nagy and T. Turányi, "Reduction of very large reaction mechanisms using methods based on simulation error minimization," Combust. Flame 156 (2) (2009) 417-428. 120. J. Y. Chen and Y. F. Tham, "Speedy solution of quasi-steady-state species by combination of fixed-point iteration and matrix inversion," Combust. Flame 153 (4) (2008) 634-646.

121. M. Janbozorgi, S. Ugarte, H. Metghalchi and J. C. Keck, "Combustion modeling of monocarbon fuels using the rate-controlled constrained-equilibrium method," Combust. Flame 156 (10) (2009) 1871-1885.

122. J. C. Keck and D. Gillespie, "Rate-Controlled Partial-Equilibrium Method for Treating Reacting Gas-Mixtures," Combust. Flame 17 (2) (1971) 237-241.

123. S. Rigopoulos and T. Løvås, "A LOI-RCCE methodology for reducing chemical kinetics, with application to laminar premixed flames," Proc. Combust. Inst. 32 (1) (2009) 569-576. 
124. K. König and U. Maas, "On-demand generation of reduced mechanisms based on hierarchically extended intrinsic low-dimensional manifolds in generalized coordinates," Proc. Combust. Inst. 32 (1) (2009) 553-560.

125. O. O. Oluwole, P. I. Barton and W. H. Green, "Obtaining accurate solutions using reduced chemical kinetic models: a new model reduction method for models rigorously validated over ranges," Combustion Theory and Modelling 11 (1) (2007) 127-146.

126. S. M. Aceves, D. L. Flowers, C. K. Westbrook, J. R. Smith, R. W. Dibble, M. Christensen, W. J. Pitz and B. Johansson, "A Multi-Zone Model for Prediction of HCCI Combustion and Emissions," SAE Paper No. 2000-01-0327, 2000.

127. G. M. Goldin, Z. Y. Ren and S. Zahirovic, "A cell agglomeration algorithm for accelerating detailed chemistry in CFD," Combustion Theory and Modelling 13 (4) (2009) 721-739.

128. R. B. Pember, L. H. Howell, J. B. Bell, P. Colella, W. Y. Crutchfield, W. A. Fiveland and J. P. Jessee, "An adaptive projection method for unsteady, low-Mach number combustion," Combust. Sci. Technol. 140 (1-6) (1998) 123-168.

129. M. J. Berger and P. Colella, "Local Adaptive Mesh Refinement for Shock Hydrodynamics," Journal of Computational Physics 82 (1) (1989) 64-84.

130. J. Ray, C. A. Kennedy, S. Lefantzi and H. N. Najm, "Using high-order methods on adaptively refined block-structured meshes: Derivatives, interpolations, and filters," Siam Journal on Scientific Computing 29 (1) (2007) 139-181.

131. M. S. Day and J. B. Bell, "Numerical simulation of laminar reacting flows with complex chemistry," Combustion Theory and Modelling 4 (4) (2000) 535-556.

132. J. B. Bell, M. S. Day, I. G. Shepherd, M. R. Johnson, R. K. Cheng, J. F. Grcar, V. E. Beckner and M. J. Lijewski, "Numerical simulation of a laboratory-scale turbulent V-flame," Proceedings of the National Academy of Sciences of the United States of America 102 (29) (2005) 10006-10011.

133. R. W. Anderson, N. S. Elliott and R. B. Pember, "An arbitrary Lagrangian-Eulerian method with adaptive mesh refinement for the solution of the Euler equations," Journal of Computational Physics 199 (2) (2004) 598-617.

134. K. He, I. P. Androulakis and M. G. Ierapetritou, "On-the-fly reduction of kinetic mechanisms using element flux analysis," Chemical Engineering Science 65 (3) 1173-1184. 135. M. A. Singer and W. H. Green, "Using adaptive proper orthogonal decomposition to solve the reaction-diffusion equation," Applied Numerical Mathematics 59 (2) (2009) 272-279. 136. G. P. Smith, D. M. Golden, M. Frenklach, N. W. Moriarty, B. Eiteneer, M. Goldenberg, C. T. Bowman, R. K. Hanson, S. Song, J. William C. Gardiner, V. V. Lissianski and Z. Qin, "GRIMech VERSION 3.0," http://www.me.berkeley.edu/gri_mech/, 1999.

137. A. Kazakov, M. Chaos, Z. W. Zhao and F. L. Dryer, "Computational singular perturbation analysis of two-stage ignition of large hydrocarbons," J. Phys. Chem. A 110 (21) (2006) 70037009 .

138. T. Lu, C. S. Yoo, J. H. Chen and C. K. Law, "Analysis of a Turbulent Lifted Hydrogen/Air Jet Flame from Direct Numerical Simulation with Computational Singular Perturbation," 46th AIAA Aerospace Sciences Meeting and Exhibit, Paper No. AIAA2008-1013, Reno, 2008. 139. L. Liang, K. Puduppakkam and E. Meeks, "Towards Using Realistic Chemical Kinetics in Multidimensional CFD " Nineteenth International Multidimensional Engine Modeling User's Group Meeting Detroit, Michigan 2009. 
140. H. R. Zhang, E. G. Eddings, A. F. Sarofim, C. L. Mayne, Z. Yang and R. J. Pugmire, "Use of Functional Group Analysis for the Selection of Surrogates for Jet Fuels," U.S. Combustion Meeting, San Diego, CA, 2007.

141. C. S. McEnally and L. D. Pfefferle, "Improved sooting tendency measurements for aromatic hydrocarbons and their implications for naphthalene formation pathways," Combust. Flame 148 (4) (2007) 210-222.

142. ASTM-International, "ASTM Standard D6890, Standard Test Method for Determination of Ignition Delay and Derived Cetane Number (DCN) of Diesel Fuel Oils by Combustion in a Constant Volume Chamber," West Conshohocken, PA, www.astm.org, 2007.

143. L. M. Pickett and D. L. Siebers, "Soot in diesel fuel jets: effects of ambient temperature, ambient density, and injection pressure," Combust. Flame 138 (1-2) (2004) 114-135.

144. Y. Ra and R. D. Reitz, "A vaporization model for discrete multi-component fuel sprays," International Journal of Multiphase Flow 35 (2) (2009) 101-117.

145. A. T. Holley, X. Q. You, E. Dames, H. Wang and F. N. Egolfopoulos, "Sensitivity of propagation and extinction of large hydrocarbon flames to fuel diffusion," Proc. Combust. Inst. 32 (1) (2009) 1157-1163.

146. L. S. Tee, S. Gotoh and W. E. Stewart, "Molecular Parameters for Normal Fluids Lennard-Jones 12-6 Potential," Industrial \& Engineering Chemistry Fundamentals 5 (3) (1966) 356-363.

147. C. Ji, E. Dames, Y. L. Wang, H. Wang and F. N. Egolfopoulos, "Propagation and extinction of premixed C5-C12 n-alkane flames," Combust. Flame In Press (2009)

148. D. R. Caudwell, J. P. M. Trusler, V. Vesovic and W. A. Wakeham, "Viscosity and Density of Five Hydrocarbon Liquids at Pressures up to $200 \mathrm{MPa}$ and Temperatures up to $473 \mathrm{~K}$," Journal of Chemical and Engineering Data 54 (2) (2009) 359-366.

149. M. A. Herna'ndez-Galva'́n, F. Garci'a-Sa'nchez, B. E. García-Flores and J. CastroArellano, "Liquid Viscosities of Cyclohexane, Cyclohexane + Tetradecane, and Cyclohexane + Benzene from (313 to 393) K and Pressures Up to 60 MPa," J. Chem. Eng. Data 54 (10) (2009) 2831-2838.

150. R. A. Perkins, U. Hammerschmidt and M. L. Huber, "Measurement and correlation of the thermal conductivity of methylcyclohexane and propylcyclohexane from (300 to 600) $\mathrm{K}$ at pressures to 60 MPa," Journal of Chemical and Engineering Data 53 (9) (2008) 2120-2127. 151. T. J. Bruno, A. Wolk and A. Naydich, "Stabilization of Biodiesel Fuel at Elevated Temperature with Hydrogen Donors: Evaluation with the Advanced Distillation Curve Method," Energy \& Fuels 23 (2) (2009) 1015-1023.

152. T. M. Lovestead and T. J. Bruno, "Application of the Advanced Distillation Curve Method to the Aviation Fuel Avgas 100LL," Energy \& Fuels 23 (4) (2009) 2176-2183.

153. M. L. Huber, E. W. Lemmon, V. Diky, B. L. Smith and T. J. Bruno, "Chemically authentic surrogate mixture model for the thermophysical properties of a coal-derived liquid fuel," Energy \& Fuels 22 (5) (2008) 3249-3257. 